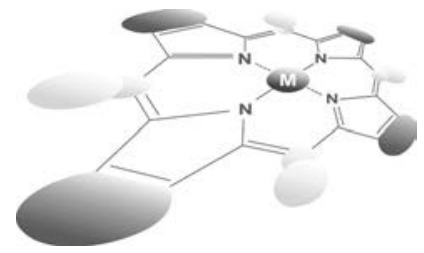

\title{
Self-organization principles in the formation of multiporphyrin complexes and "semiconductor quantum dot-porphyrin" nanoassemblies
}

\author{
Eduard I. Zenkevich ${ }^{\star a}$ and Christian von Borczyskowski ${ }^{b}$ \\ ${ }^{a}$ National Technical University of Belarus, Department of Information Technologies and Robotics, \\ Nezavisimosti Ave., 65, Minsk 220013, Belarus \\ ${ }^{\mathrm{b}}$ Institute of Physics and Center for Nanostructured Materials and Analytics (NanoMA), \\ Chemnitz University of Technology, 09107 Chemnitz, Germany
}

Dedicated to Professor Aslan Tsivadze on the occasion of his 70th birthday

Received 14 August 2013

Accepted 4 October 2013

\begin{abstract}
In this paper, we review several aspects of molecular recognition (based on non-covalent binding interactions) occurring between meso-pyridyl substituted tetrapyrrole extra-ligands and chemical dimers of tetrapyrrolic macrocycles containing central $\mathrm{Zn}$ ions and spacers of various nature and flexibility. Experimental results obtained by us earlier are analyzed using a novel approach (based on steady-state absorption/fluorescence measurements) for the evaluation of complexation constants $\mathrm{K}_{\mathrm{C}}$ for the formation of porphyrin triads. It was found that $\mathrm{K}_{\mathrm{C}}$ values $\left[\mathrm{K}_{\mathrm{C}} \sim(0.5-70) \times 10^{6} \mathrm{M}^{-1}\right]$ show noticeable dependence on the structural parameters of the interacting subunits as well as on the solvent nature. The same self-assembly approach has been used to attach meso-pyridyl substituted porphyrins to the surface of semiconductor $\mathrm{CdSe} / \mathrm{ZnS}$ quantum dots (QD). It was comparatively found that in contrast to self-assembled porphyrin triads, the formation of "QD-porphyrin" nanoassemblies takes place in competition with surface stabilizing tri- $n$-octyl phosphine oxide (TOPO) ligand molecules and attached porphyrin molecules. It manifests in a temporal dynamics of QD photoluminescence caused by ligand exchange, TOPO layer reorganization, QD surface reconstruction, solvent properties. It was shown that the sensitivity of QD surface morphology to attached organic ligands (e.g. porphyrins) provides an opportunity to control the dynamics and pathways of the exciton relaxation in "QD-dye" nanoassemblies by changing the structure and electronic properties of these ligands.
\end{abstract}

KEYWORDS: porphyrins, chemical dimers, self-assembly, extra-ligation, coordination interactions, complexation constants, energy/electron transfer, photoluminescence quenching, semiconductor quantum dots, ligand exchange dynamics, interface effects.

\section{INTRODUCTION}

Over the past decades nanostructured materials with tuneable morphology and functionality have attracted exceptional interest due to their unique architectures, tailored physicochemical properties as well as central roles in fabricating nanoelectronics, and potential applications in bionanotechnology [1-10]. Recently, great efforts have

*Correspondence to: Eduard I. Zenkevich, email: zenkev@tut. by, tel: +375 1293-9123, fax: +375 172-92-7153 been devoted to bottom-up self-assembled nanostructures. Self-assembly is the fundamental phenomenon that generates structural organization on all scales in vivo and in vitro [11]. The most important source of inspiration for self-assembly strategies is natural photosynthesis in which the generation of complex, multicomponent threedimensional structures involves intramolecular, as well as intermolecular and interfacial interactions [12-14].

In the organic world, the preparation of supramolecular complexes in which organic compounds present a high degree of order, which spans from the nanoscopic to the 
macroscopic level across multiple length scales, is highly desirable and represents a key issue within the fast-growing fields of nanoscience and nanotechnology [15-17]. The interest in self-assembled organic nanostructures (including those based on tetrapyrrolic macrocycles) is growing exponentially because of few reasons. Firstly, they are often used as good models for mimicking the primary photochemical processes in vivo. Secondly, such complexes seem to be considered as promising building blocks for advanced multifunctional nanocomposites with potential applications in multimolecular architectures for information storage, nanovoltaic cells, optoelectronic memory, drug delivery systems, photodynamic therapy, etc. [18-26].

It should be mentioned that the field of nanoscience and nanotechnology involves also inorganic systems of nanoscale dimensions. In this connection, semiconductor nanocrystals (often referred to as quantum dots, QD, e.g. CdSe or $\mathrm{CdSe} / \mathrm{ZnS}$ and other II-VI systems) represent a specific class of matter between atomic clusters and bulk materials with well-defined size-dependent tunable photophysical properties [27-30]. Further, using the self-assembly approach the anchoring of functional organic molecules (including porphyrins and other heteromacrocycles) and even proteins to the QD surface has been realized to form organic/inorganic nanocomposites, being of considerable scientific and a wide practical interest including material science and biomedical applications [31-40].

From physico-chemical point of view some common moments should be taken into account for both selforganized supramolecular complexes and "QD-Organic molecule" nanoassemblies. One of the first and necessary stages should be devoted to the quantitative study of the subunit ability to the specific selective interactions. Namely these interactions are responsible for the formation of stable complexes or nanoassemblies with demanded functional properties (such as energy or charge transfer, catalytic activity, photodynamic efficiency, etc.). In its turn, the thermodynamics of interactions may depend also on the solvent properties (different solubility of interacting moieties, polarity, temperature, etc.).

In the case of multiporphyrin complexes, we have developed a concept to self-assemble porphyrin (or chlorin) arrays which may show tuneable photoinduced energy/electron transfer and charge separation. The keylock organization principle is based on the complexation of central $\mathrm{Zn}$ ions of porphyrin chemical dimers (or trimers) of various structures with suitable extra-ligands (mono, di- and tetrapyridyl substituted tetrapyrrole macrocycles) via two-fold non-covalent coordination [17, 41-44]. Correspondingly, the geometry and flexibility of the spacer as well as the matching geometry between $\mathrm{N}$ atoms in pyridyl containing extra-ligands and $\mathrm{Zn}-\mathrm{Zn}$ distance in the dimers (or trimers) should play the essential role in the formation of multiporphyrin complexes with relatively well-defined conformational rigidity and a controlled number of electronically interacting chromophores. In this paper, we will discuss these factors.
On the basis of our experience on the formation of self-assembled multiporphyrin complexes mentioned above, we have elaborated the experimental approach in the direct attachment of functional dye molecules to the surface of semiconductor $\mathrm{CdSe}$ or $\mathrm{CdSe} / \mathrm{ZnS}$ quantum dots in solutions. Meso-pyridyl substituted porphyrins and pyridyl functionalized perylene diimides were used to interact with QDs capped by trioctylphosphine oxide (TOPO) or long chain amine (AM) molecules [45-50]. With respect to formation and possible applications of these nanoassemblies in liquid or solid phase (e.g. in sensing phenomena or photodynamic therapy) several factors seem to be of essential importance: (i) attachment/ detachment of dye molecules [51-53], (ii) the interplay of dye molecule attachment and capping ligand exchange dynamics $[54,55]$ and (iii) the presence and formation of various surface trap states in the band gap $[56,57]$ whose energies and properties may be changed upon interface reconstruction (via polarity and/or temperature change) or competing ligand/dye exchange dynamics.

With these ideas in mind, the goal of the present paper is the comparative analysis of the self-assembly effects in multiporphyrin complexes and in inorganic-organic "QD-porphyrin" nanoassemblies based on our experimental results and theoretical considerations. The main experimental results for the two types of self-assembled complexes have been described by us recently [17, 49, 50]. Nevertheless, for the reader benefit, typical structural and spectral information is presented in the corresponding sections of the given manuscript. In addition, a novel approach (based on steady-state absorption/fluorescence measurements) for the evaluation of complexation constants $\mathrm{K}_{\mathrm{C}}$ for the formation of porphyrin triads as well as for "QD-porphyrin" nanoassemblies is described in this paper followed by the analysis of equilibrium constants for the complexes under study. We like to point out that this contribution should be considered as a review of a likewise comparative characterization of the non-covalent self-assembly possibilities for the directed construction of multiporphyrin complexes with variation of interacting subunits as well as the influence of interface properties and competitive ligand exchange dynamics on the formation of "QD-porphyrin" nanoassemblies.

\section{EXPERIMENTAL}

\section{Functional tetrapyrrole compounds}

For the construction of highly organized and relatively rigid triads of tetrapyrrole compounds we have used the combination of the covalent linkage and non-covalent self-assembly [17, 39, 41-44]. One type of precursor molecular blocks is presented by Zn-porphyrin or Zn-chlorin chemical dimers which have been synthesized, identified and purified by Dr. A. Shulga (Minsk, Belarus) and described earlier 
$[17,44]$. In three dimers porphyrin macrocycles are coupled via a rigid phenyl spacer: 1,4-bis $\{$ [zinc(II)]5$(2,3,7,8,12,13,17,18$-octaethylporphyrinyl)] $\}$ benzene, $(\mathrm{ZnOEP})_{2} \mathrm{Ph} ; 1,4$-bis $\{$ [zinc(II) $] 5-(10,15,20$-tris $(p$-hexylphenyl)-porphyrinyl)]\} benzene, (ZnHTPP) $)_{2}$, and 1,4bis-\{[zinc(II)]5-(10,15,20-phenyl)-porphyrinyl)] $\}$ benzene, $(\mathrm{ZnTPP})_{2}$. In the other two dimers monomeric tetrapyrroles are linked by a $-\mathrm{CH}_{2}-\mathrm{CH}_{2}-$ spacer via mesoposition: 1,2-bis \{5[zinc(II)octaehtylporphyrinyl]\}ethane, $(\mathrm{ZnOEP})_{2}$, and 1,2-bis $\{\gamma$-[zinc(II)octaehtylchlorinyl] $\}$ ethane, $(\mathrm{ZnOEChl})_{2}$. The structures of these dimers are presented in Fig. 1 by numbers 1-5. Monomeric

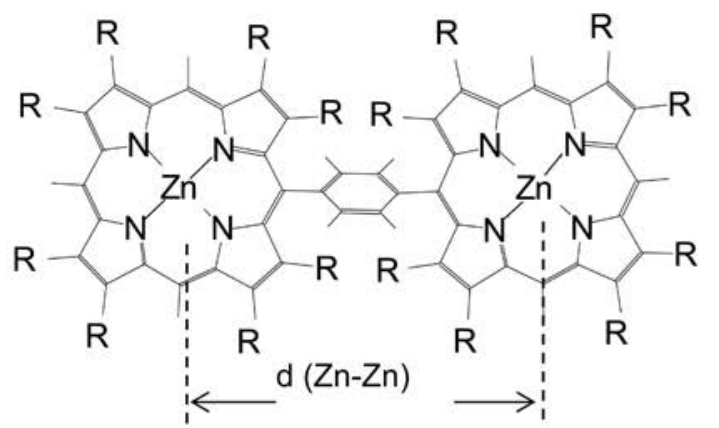

\section{1 \\ $(\mathrm{ZnOEP})_{2} \mathrm{Ph}$}

$$
\mathrm{R}=\mathrm{C}_{2} \mathrm{H}_{5}
$$

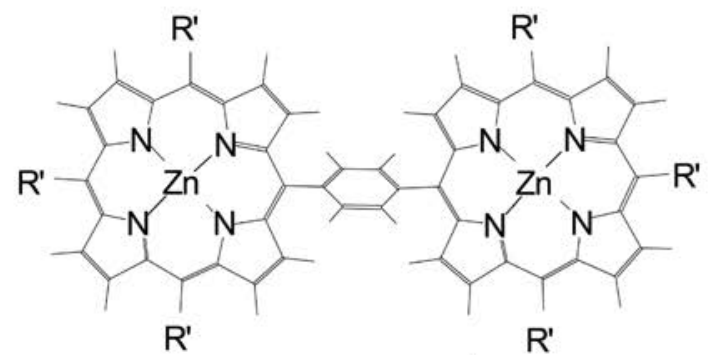

\author{
2, 3 \\ $(\mathrm{ZnHTPP})_{2}: \mathrm{R}^{\prime}=\mathrm{HexPh}$ \\ $(\mathrm{ZnTPP})_{2}: \quad \mathrm{R}^{\prime}=\mathrm{Ph}$
}

$\mathrm{HexPh}$ :

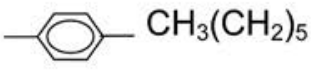

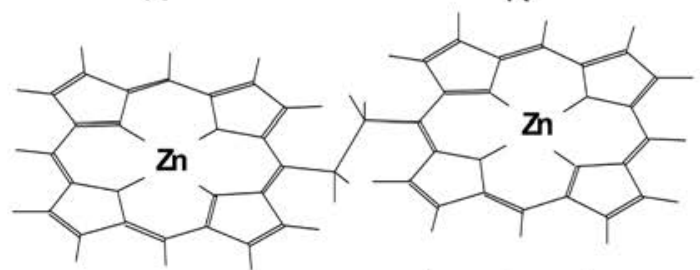

4

$(\mathrm{ZnOEP})_{2}$

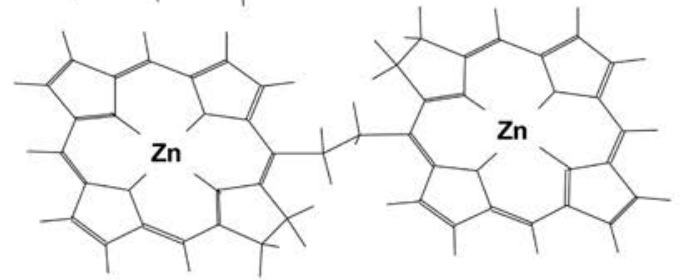

5

$(\mathrm{ZnOEChl})_{2}$

\title{
Meso-pyridyl substituted porphyrins $\left(\mathrm{H}_{2} \mathrm{P}\right)$
}

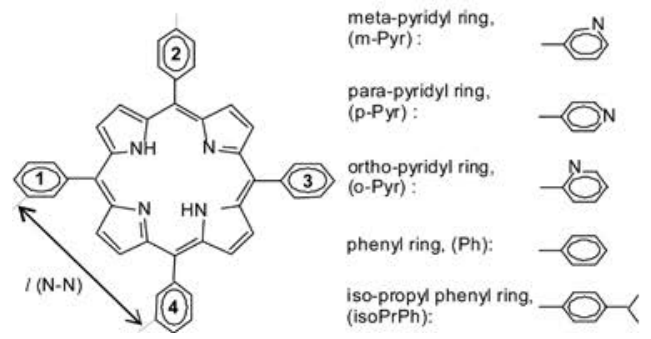

$$
\begin{aligned}
& \mathrm{H}_{2} \mathrm{P}-(\mathrm{m}-\mathrm{Pyr})_{1}: 1=(\mathrm{m}-\mathrm{Pyr}), 2,3,4=(\mathrm{Ph}) \\
& \mathrm{H}_{2} \mathrm{P}-\left(\mathrm{m}^{\wedge} \mathrm{Pyr}\right)_{2}: 1,2=(\mathrm{m}-\mathrm{Pyr}), 3,4=(\text { iso-PrPh }) \\
& \mathrm{H}_{2} \mathrm{P}-(\mathrm{m}-\mathrm{Pyr})_{2}: 1,3=(\mathrm{m}-\mathrm{Pyr}), 2,4=(\text { iso-PrPh }) \\
& \mathrm{H}_{2} \mathrm{P}-(\mathrm{m}-\mathrm{Pyr})_{3}: 1,2,3=(\mathrm{m}-\mathrm{Pyr}), 4=(\mathrm{Ph}) \\
& \mathrm{H}_{2} \mathrm{P}-\left(\mathrm{p}^{\wedge} \mathrm{Pyr}\right)_{2}: 1,2=(\mathrm{p}-\mathrm{Pyr}), 3,4=(\mathrm{Ph}) \\
& \mathrm{H}_{2} \mathrm{P}-(\mathrm{m}-\mathrm{Pyr})_{4}: 1,2,3,4=(\mathrm{m}-\mathrm{Pyr}) \\
& \mathrm{H}_{2} \mathrm{P}-(\mathrm{o}-\mathrm{Pyr})_{4}: 1,2,3,4=(\mathrm{o}-\mathrm{Pyr})
\end{aligned}
$$

Fig. 1. Structures of chemical dimers and meso-pyridyl substituted monomeric porphyrin extra-ligands used for the formation of selfassembled nanostructures: $(\mathrm{ZnOEP})_{2} \mathrm{Ph}(\mathbf{1}),(\mathrm{ZnHTPP})_{2}(\mathbf{2})$ and $(\mathrm{ZnTPP})_{2}(\mathbf{3})$ are chemical dimers with a phenyl spacer; $(\mathrm{ZnOEP})_{2}$ (4) and $(\mathrm{ZnOEChl})_{2}(\mathbf{5})$ denote chemical dimers having a single $-\mathrm{CH}_{2}-\mathrm{CH}_{2}-$ bond between macrocycles. The corresponding side substituents $\mathrm{R}$ and $\mathrm{R}^{\prime}$ are shown for compounds 1-3; in dimers $\mathbf{4}$ and $\mathbf{5} \beta$-alkyl substituents are omitted for clarity. For meso-pyridyl substituted porphyrins the basic chemical structure is presented together with positions of pyridyl-substituents and the corresponding abbreviations. $\mathrm{d}(\mathrm{Zn}-\mathrm{Zn})$ denotes the distance between central $\mathrm{Zn}$ ions in the dimers; $1(\mathrm{~N}-\mathrm{N})$ denotes the distance between $\mathrm{N}$ atoms in pyridyl rings participating in the self-assembly process 

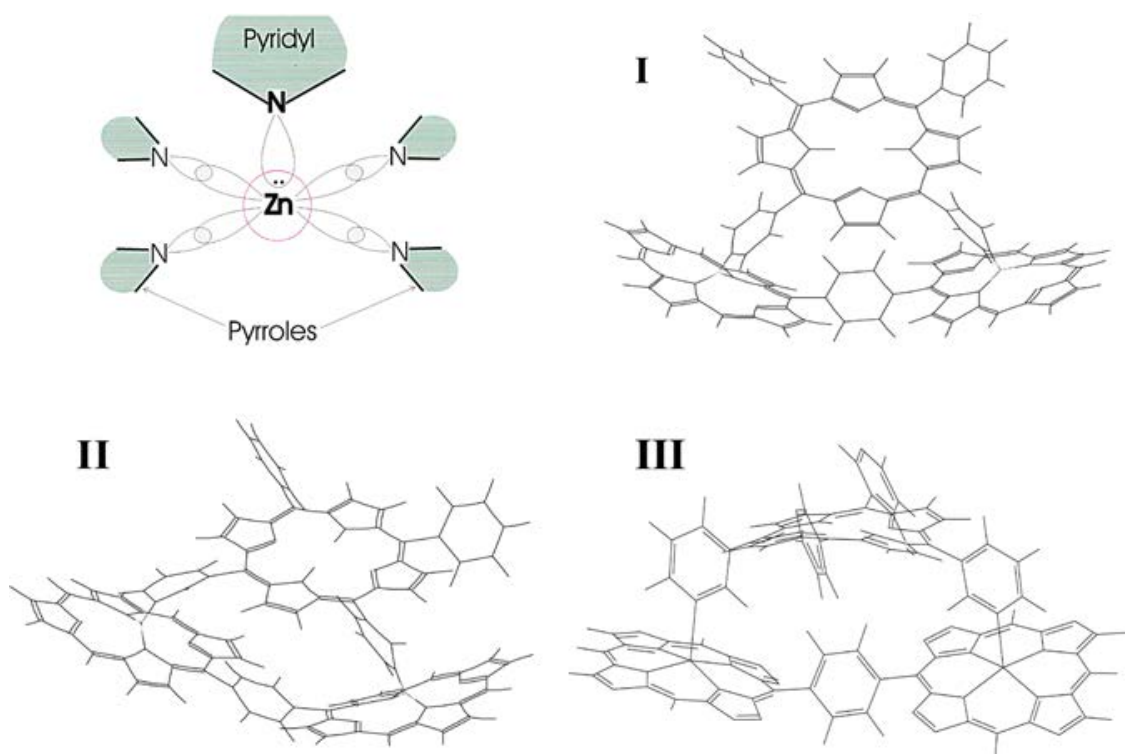

Fig. 2. A schematic representation (up-left) of coordination interaction between central Zn ion of the porphyrin macrocycle with $\mathrm{N}$ atom of the pyridyl ring (N-pyr) as well spatial arrangement of the dimers, $(\mathrm{ZnHTPP})_{2},(\mathrm{ZnOEP})_{2} \mathrm{Ph}$ and various extra-ligands in self-assembled triads (HyperChem software package, release 4, semiempirical methods AM1 and PM3): (I) triad with extra-ligand having adjacent para-pyridyl rings, $(\mathrm{ZnHTPP})_{2} \otimes \mathrm{H}_{2} \mathrm{P}-\left(\mathrm{p}^{\wedge} \mathrm{Pyr}\right)_{2} ;$ (II) triad with extra-ligand having adjacent meta-pyridyl rings, $(\mathrm{ZnHTPP})_{2} \otimes \mathrm{H}_{2} \mathrm{P}-\left(\mathrm{m}^{\wedge} \mathrm{Pyr}\right)_{2} ;($ III $)$ triad with extra-ligand having opposite meta-pyridyl rings, $(\mathrm{ZnHTPP})_{2} \otimes \mathrm{H}_{2} \mathrm{P}-(\mathrm{m}-\mathrm{Pyr})_{2}$. Symbol $\otimes$ shows what components are coupled in the triad. For simplicity, meso-phenyl rings in the dimer $(\mathrm{ZnHTPP})_{2}$ are omitted and most of the phenyls rings in extra-ligands are missing double bonds too

meso-pyridyl substituted porphyrins, $\mathrm{H}_{2} \mathrm{P}$, chlorins, $\mathrm{H}_{2} \mathrm{Chl}$, and tetrahydroporphyrins, $\mathrm{H}_{2}$ THP are the other type of precursors. These compounds have been also synthesized, identified and purified by Dr. A. Shulga (Minsk, Belarus) and described elsewhere [17, 44]. The basic chemical structure of these extra-ligands is presented in Fig. 1 together with positions of pyridyl-substituents and the corresponding abbreviations. As was mentioned above, the basic key-lock principle of a self-assembled triad formation is connected with coordination interactions of the porphyrin central $\mathrm{Zn}$ ions with appropriate pyridyl rings of extra-ligands. Such a synthetically elegant route to form a wide variation of multiporphyrin systems is often used and greatly reduces the assemblies' synthetic difficulties, though the mutual arrangement of interacting subunits is subject to some restrictions [58-63]. Figure 2 shows a schematic representation of coordination interaction between central $\mathrm{Zn}$ ion of the porphyrin dimer macrocycle with $\mathrm{N}$ atom of the pyridyl ring (N-pyr) as well the main structures of the triads being obtained and analyzed in the given paper.

\section{Semiconductor quantum dots and "QD-porphyrin" nanoassemblies}

For steady-state absorption and fluorescence experiments highly monodisperse colloidal core/shell CdSe/ ZnS QDs capped by tri- $n$-octyl phosphine oxide (TOPO) were obtained from Evident Technologies, Inc, Troy, NY, USA. Structural, spectral-kinetic and physico-chemical properties of studied CdSe/ZnS QDs, characterized by size-dependent quantum confinement effects [27-30], have been described by us earlier [45, 48-50]. When providing experiments, stability and purity of the QD solutions were checked by measuring the quantum yield stability at least over $3 \mathrm{hrs}$ after preparation. The self-assembled formation of "QD-porphyrin" nanoassemblies has been also realized via coordination of meso-pyridyl-substituted porphyrin ligands with surface $\mathrm{Zn}$ ions of inorganic $\mathrm{ZnS}$ shell covering CdSe core. In Fig. 3 schematic presentation of the geometry for "QD-porphyrin" nanoassemblies and relative sizes of the main components are presented.

\section{Sampling and experimental set-up}

Quantitative titration experiments have been performed at ambient conditions in toluene (Tol), cyclohexane $(\mathrm{CH})$, methylcyclohexane $(\mathrm{MCH})$, and/or $\mathrm{Tol}+\mathrm{CH}$ solvent (1:6) mixture. All solvents were spectroscopic grade (Fluka SeccoSolv or Merck dried with a molecular sieve). The optical cuvettes (Hellma QS-111, path length $1 \mathrm{~cm}$ ) and other glassware were flushed with acetone and ethanol, chemically cleaned with aqueous $\mathrm{H}_{2} \mathrm{SO}_{4}: \mathrm{H}_{2} \mathrm{O}_{2}$, flushed with deionized water, dried in a nitrogen flow and purged with toluene.

The triads were formed at ambient temperature during a standard titration of the chemical dimer solution $\left(\mathrm{C}_{\mathrm{D} 0} \sim\right.$ $1 \times 10^{-6} \mathrm{M}-4 \times 10^{-6} \mathrm{M}$ ) with a high concentrated solution of extra-ligand monomeric molecules $\left(\mathrm{C}_{\mathrm{L}} \sim 0.3 \times 10^{-4} \mathrm{M}-\right.$ $\left.2 \times 10^{-4} \mathrm{M}\right)$. Aliquots of porphyrin ligand were added in 

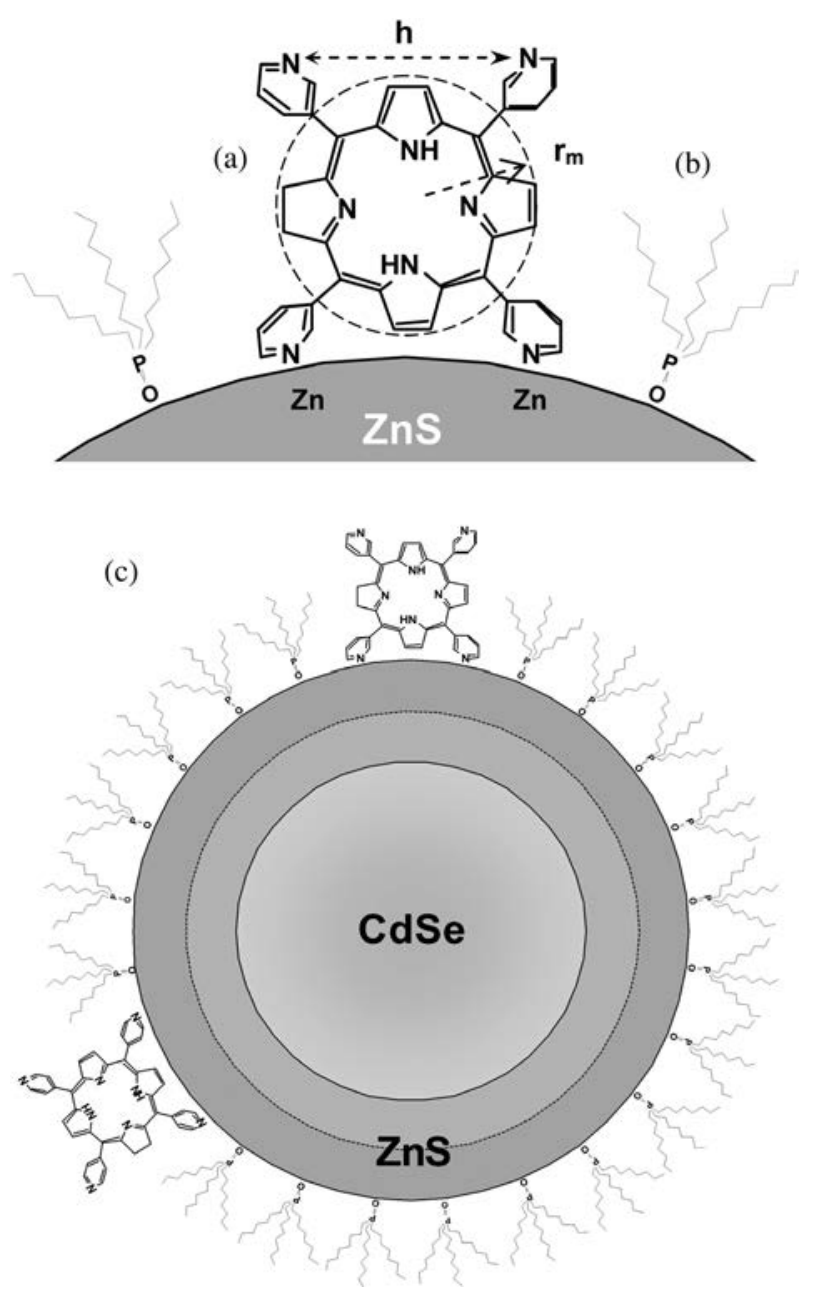

Fig. 3. Structure of $\mathrm{H}_{2} \mathrm{P}-(\mathrm{m}-\mathrm{Pyr})_{4}$ molecule (a), trioctylphosphine oxide, TOPO, molecule (b) as well as schematic presentation of "QD-Porphyrin" nanoassemblies (c). In part C the scales of CdSe core, $\mathrm{ZnS}$ shell, porphyrin and TOPO molecules correspond to relative sizes of the main components of the real "QD-Porphyrin" nanoassemblies: the ZnS shell thickness for QDs was estimated on the basis of the thickness of one $\mathrm{ZnS}$ layer $1=5 \AA$; parameters for conical TOPO molecules $\mathrm{r}_{\text {bottom }}=5.5 \AA$, $\mathrm{h}_{\mathrm{con}}=9.9 \AA ; \mathrm{r}_{\mathrm{m}}=7.5 \AA$ is the radius of porphyrin molecule with opposite pyridyl rings having nitrogens in meta-positions, $\mathrm{h}=$ $10 \AA$ is the mean distance between meta-nitrogens of adjacent pyridyl rings (HyperChem 4.0, semiempirical method PM3). Optimized geometry for $\mathrm{Cd}_{33} \mathrm{Se}_{33}+\mathrm{H}_{2} \mathrm{P}-\left(\mathrm{m}^{\wedge} \mathrm{Pyr}\right)_{2}$ complex has been obtained using HyperChem 7.0 and simulations by $a b$ initio density functional theory, DFT, with the VASP code [64]).

steps of $10-20 \mu \mathrm{L}$ to the dimer dissolved in $2.6 \mathrm{~mL}$ of toluene, giving molar ratios of $x=\left[\mathrm{C}_{\mathrm{L}}\right] /\left[\mathrm{C}_{\mathrm{D} 0}\right]=0.1-20$. Absorption and fluorescence spectra have been measured after each step of the titration procedure. The step, at which no further changes in absorption of the dimer were detected within experimental error, was considered as the final point of the titration procedure.

The experimental approach for the formation of "QD-porphyrin" nanoassemblies was the same as for multiporphyrin complexes. The initial concentration of
$\mathrm{QD}$ in solutions was in the range of $\mathrm{C}_{\mathrm{QD}}(1-2) \times 10^{-7}$ M. The absorbance of the QD starting toluene solution was adjusted to be lower than 0.1 OD at excitation and emission wavelengths in order to avoid non-linear absorption and re-absorption effects. Porphyrins were sequentially added in steps of $10 \mu \mathrm{l}$ from a highly concentrated stock solution $\left(\mathrm{C}_{\mathrm{L}} \sim 8 \times 10^{-6}-4 \times 10^{-5} \mathrm{M}\right)$ up to wanted molar ratios $x=\left[\mathrm{C}_{\mathrm{L}}\right] /\left[\mathrm{C}_{\mathrm{QD}}\right]$. For quantitative comparison and reproducibility of titration curves for "QD-porphyrin" nanoassemblies it was necessary to perform experiments under exactly the same procedures of the initial QD sample preparation and to wait approx. $30 \mathrm{~min}$ for the sample emission stabilization. Every sequential titration step including spectral measurements was separated by $\sim 7-10 \mathrm{~min}$.

Standard scanning spectrophotometers (Shimadzu 3001 UV-vis and/or Cary-500 M Varian) were used for absorption measurements. Emission spectra were measured with a SFL-1211A (Solar, Belarus) and/or Shimadzu RF-5001PC spectrofluorimeters (calibrated for the spectral response of the detection channel against a set of fluorescence standards).

\section{RESULTS AND DISCUSSION}

\section{Self-assembled tetrapyrrole triads}

Formation of porphyrin triads and evaluation of complexation constants $\boldsymbol{K}_{\boldsymbol{C}}$. In non-polar solvents at 293 $\mathrm{K}$, during a titration of a solution with a given chemical dimer by added amounts of various meso-pyridylcontaining extra-ligands, spectral transformations of steady-state absorption and fluorescence data provide clear evidence for the formation of self-assembled complexes, which is typical for a lot of systems under study [17, 41-44]. The main observations are collected in Fig. 4 for the dimer $(\mathrm{ZnOEP})_{2} \mathrm{Ph}$ and extra-ligand $\mathrm{H}_{2} \mathrm{P}$ $(\mathrm{m}-\mathrm{Pyr})_{2}$-(iso-PrPh $)_{2}$. It seen that upon complexation of the dimer with dipyridyl containing $\pi$-conjugated macrocycles the visible absorption bands of the dimer are shifted to the red $\left(\Delta v \sim 450 \mathrm{~cm}^{-1}\right)$ with essential intensity redistribution. The spectral transformations are very similar to the effects taking place for the complexes of various $\mathrm{Zn}$-porphyrins and their chemical dimers with pyridine or numerous pyridyl containing molecules [41, 65-68]. These axial extra-ligation effects are explained in the frame of Gouterman four-orbital model by relative changes of energies of HOMO's $a_{1 u}$ and $a_{2 u}$ [69]. In addition, absorption spectra of the triads are essentially a linear combination of the corresponding dipyridinated dimer and extra-ligand, with only small differences in wavelength maxima and band shapes. It means that the interaction between the two subunits is weak in the ground state, and they retain their individual identities.

Notably, in the range of intense absorption bands of the dimers the influence of added amounts of extra-ligands 

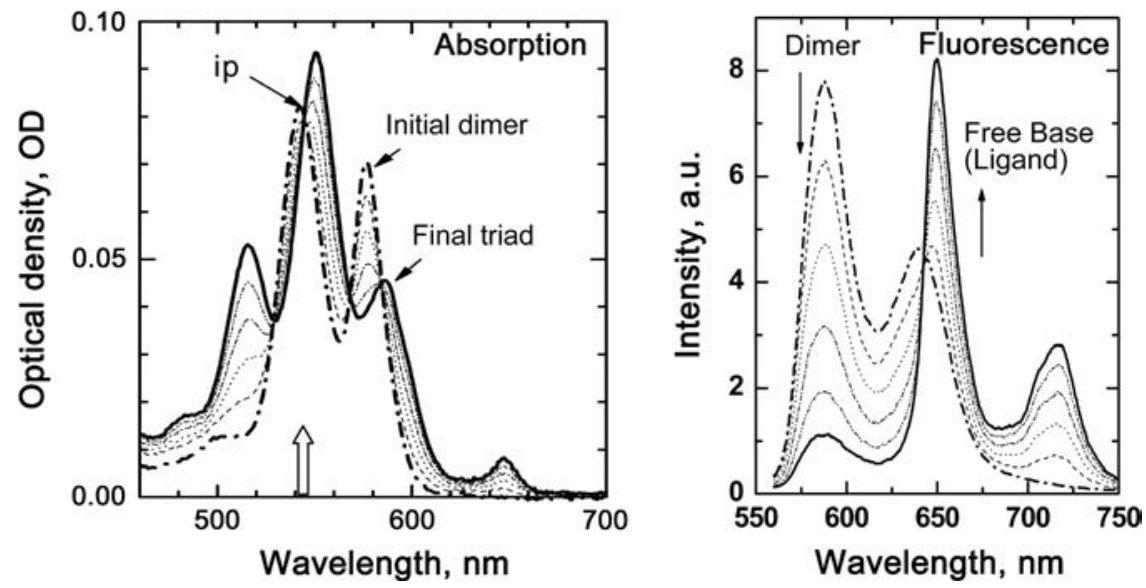

Fig. 4. Absorption and fluorescence spectra of the dimer $(\mathrm{ZnOEP})_{2} \mathrm{Ph}$ with increasing amounts of the porphyrin extra-ligand $\mathrm{H}_{2} \mathrm{P}\left(\mathrm{m}^{\wedge} \mathrm{Pyr}\right)_{2}$-(iso- $\left.\mathrm{PrPh}\right)_{2}$ in toluene at $293 \mathrm{~K}$. Concentration of $(\mathrm{ZnOEP})_{2} \mathrm{Ph}$ at the beginning of titration is $\mathrm{C}_{\mathrm{D} 0}=1.9 \times 10^{-6} \mathrm{M}$. The ligand/dimer molar ratio $x=\left[\mathrm{C}_{\mathrm{L}}\right] /\left[\mathrm{C}_{\mathrm{DO}}\right]$ varies from $x=1: 0$ to $1: 1(0.0,0.2,0.4,0.6,0.8,1.0)$. Bold curves correspond to the triad spectra. The low-intense unshifted fluorescence band at $\lambda_{\max }=586 \mathrm{~nm}$ in triad solution at $x=1: 1$ belongs to the remaining uncomplexed dimer. Isosbestic point in absorption spectra $(\lambda=546 \mathrm{~nm})$ is shown by black circle. All solutions have been excited at the wavelength corresponding to the isosbestic point (ip, shown by wide arrow in left figure)

is very low. Thus, during titration few isosbestic points are observed in absorption spectra of mixed solutions (one is shown in Fig. 4) indicating the complexation of the dimers with extra-ligands. Interestingly also that for triads of various geometry (I-III in our case) with all extra-ligands, the dimer fluorescence does show strong quenching (fluorescence decay is shorten from $\tau_{\mathrm{SD}}{ }^{0}=$ $1.15 \mathrm{~ns}$ down to $\tau_{\mathrm{SD}} \times 1.4 \mathrm{ps}$ for the triad $\mathbf{I}$ in toluene at $293 \mathrm{~K}[42,70])$, and fluorescence spectra of the triads mainly consist of the porphyrin extra-ligand fluorescence bands (see Fig. 4). Based on steady-state, time-resolved fluorescent and pump-probe results in combination with theoretical considerations it was proven $[17,42,70]$ that this quenching is due to competing energy migration and photoinduced electron transfer processes. Summarizing, both these facts (the existence of isosbestic points and strong quenching of the dimer emission) will be used below upon evaluation of complexation constants.

In general, UV-vis spectrophotometric methods are highly sensitive and as such are suitable for studying complexation equilibrium in solutions [71-73]. However, in many cases, the spectral responses of two and sometimes even more components overlap considerably and analysis is no longer straightforward and needs using some complex mathematical algorithms [74-77]. In such complicated situation, the additional use of fluorescence approach may be employed for the determination of the complexation constants. The main idea is based on the fluorescence quenching of a given component (probe) upon complexation with or incorporation into other component, and the treatment of the data is independent of the quenching mechanism [78]. Namely this situation is typical in our case (see Fig. 4): upon complexation the dimer fluorescence does show strong quenching, and during titration few isosbestic points are observed in absorption spectra of mixed solutions.

With this idea in mind and taking into account the two facts mentioned above for our systems, we propose the following way for the evaluation of complexation constants for the triad formation. In the later case, considering the one step triad formation at given temperature, the equilibrium concentrations of the triad $\left[\mathrm{C}_{\mathrm{T}}\right]$, uncomplexed $\mathrm{Zn}$-porphyrin dimer $\left[\mathrm{C}_{\mathrm{D}}\right]$ and uncomplexed extra-ligand $\left[\mathrm{C}_{\mathrm{L}}\right]$ are related by the well-known law of mass action [78].

Correspondingly, at equilibrium conditions the complexation constant $\mathrm{K}_{\mathrm{C}}$ is written as;

$$
\begin{aligned}
& \mathrm{C}_{\mathrm{T}} \underset{\left[\mathrm{k}_{1}\right]}{\stackrel{\left[\mathrm{k}_{2}\right]}{\rightleftarrows}} \mathrm{C}_{\mathrm{D}}+\mathrm{C}_{\mathrm{L}} . \\
& \mathrm{K}_{\mathrm{C}}=\frac{\mathrm{k}_{1}}{\mathrm{k}_{2}}=\frac{\mathrm{C}_{\mathrm{T}}}{\mathrm{C}_{\mathrm{D}} \times \mathrm{C}_{\mathrm{L}}}
\end{aligned}
$$

where $\mathrm{k}_{1}$ and $\mathrm{k}_{2}$ are rates of forward and back reactions.

In our case, the existence of isosbestic points means that upon one-step complexation there is one transition from initial two substances (dimer and ligand) to triad without formation of intermediate absorbing products. Additionally, the strong quenching of the dimer fluorescence in the triad may be used for the direct estimation of the concentration of uncomplexed Zn-porphyrin dimer $\left[C_{D}\right]$ at every step of the titration process. Consequently, at the beginning of the titration process, the fluorescence intensity (maximum value or integrated over the band) of pure dimer upon excitation at isosbestic point $\lambda_{\text {iso }}$ is written by the following way [79];

$$
\begin{aligned}
\mathrm{F}_{\mathrm{D} 0} & =\alpha \times \mathrm{I}_{0} \times \varphi_{0}\left[1-\exp \left(-\varepsilon_{\mathrm{D}} \mathrm{C}_{\mathrm{D}} \mathrm{I}\right) \times 1\right] \\
& =\alpha \times \mathrm{I}_{0} \times \varphi_{0}\left[1-\mathrm{T}_{\mathrm{D} 0}\right]
\end{aligned}
$$


where $\alpha=$ const is factor determining excitation/ registration conditions; $I_{0}$ is the intensity of exciting light (constant during titration process); $\varphi_{0}=$ const is the pure dimer fluorescence quantum efficiency; $\varepsilon_{\mathrm{D}}$ is molar decimal extinction coefficient of the dimer at $\lambda_{\text {iso }} ; l$ is an optical length of a solution; $\mathrm{T}_{\mathrm{D} 0}$ is the transparence of the pure dimer solution. In mixed solutions at excitation into isosbestic point $\lambda_{\text {iso }}$ one may neglect the absorption of the added extra-ligand that is $\varepsilon_{\mathrm{D}}=\varepsilon_{\mathrm{T}} \gg \varepsilon_{\mathrm{L}}$, where $\varepsilon_{\mathrm{T}}$ and $\varepsilon_{\mathrm{L}}$ are molar decimal extinction coefficients of the triad and extra-ligand, correspondingly. At these excitation conditions, the whole fluorescence intensity of the mixed solution in the region of the dimer emission band can be presented in the form;

$$
\begin{aligned}
\mathrm{F}_{\mathrm{D}} & =\alpha \times \mathrm{I}_{0} \times \varphi_{0} \frac{\varepsilon_{\mathrm{D}} \mathrm{C}_{\mathrm{D}}}{\varepsilon_{\mathrm{D}} \mathrm{C}_{\mathrm{D}}+\varepsilon_{\mathrm{T}} \mathrm{C}_{\mathrm{T}}}\left[1-\exp \left(-\varepsilon_{\mathrm{D}} \mathrm{C}_{\mathrm{D}}-\varepsilon_{\mathrm{T}} \mathrm{C}_{\mathrm{T}}\right) \times \mathrm{I}\right] \\
& =\alpha \times \mathrm{I}_{0} \times \varphi_{0} \frac{\varepsilon_{\mathrm{D}} \mathrm{C}_{\mathrm{D}}}{\varepsilon_{\mathrm{D}} \mathrm{C}_{\mathrm{D}}+\varepsilon_{\mathrm{T}} \mathrm{C}_{\mathrm{T}}}\left[1-\mathrm{T}_{\Sigma}\right]
\end{aligned}
$$

where $\mathrm{T}_{\mathrm{D} 0}$ is the transparence of the mixed solution at a given titration step. Thus, taking into account that $\mathrm{C}_{\mathrm{D}}+$ $\mathrm{C}_{\mathrm{T}}=\mathrm{C}_{\mathrm{D} 0}$ and $\left[1-\mathrm{T}_{\mathrm{D} 0}\right]=\left[1-\mathrm{T}_{\Sigma}\right]$ at every titration step it follows from Equations 3 and 4 that the portion of noncomplexed dimer $\beta$ may be estimated from the relative intensity ratio;

$$
\beta=\frac{C_{D}}{C_{D 0}}=\frac{F_{D}}{F_{D 0}}
$$

Typically, in titration experiments initial volumes of the dimer solution were $\mathrm{V}_{0} \sim 2.5-3.0 \mathrm{~mL}$ while added volumes of extra-ligand were $\Delta \mathrm{V} \sim 10-20 \mu \mathrm{l}$ at every titration step. Thus, experimental error of intensity $\mathrm{F}$ measurements caused by dilution of the dimer initial solution did not exceed 3\%. Consequently, for every given molar ratio $x=$ $\mathrm{C}_{\mathrm{L}} / \mathrm{C}_{\mathrm{D} 0}$ upon titration and excitation at isosbestic point $\lambda_{\text {iso }}$ by using Equations 1, 2 and 5 the following equation for complexation constant $\mathrm{K}_{\mathrm{C}}$ can be derived;

$$
K_{C}=\frac{1-\beta}{C_{D 0} \times \beta(x+\beta-1)}
$$

$\mathrm{K}_{\mathrm{C}}$ values for every self-assembled system have been evaluated from experimental dependences $\beta=F_{D} / F_{D 0}$ values vs. molar ratio $x=\mathrm{C}_{\mathrm{L}} / \mathrm{C}_{\mathrm{D} 0}$ which have been leastsquare fitted using expressions;

$$
\begin{aligned}
\beta=\frac{F_{D}}{F_{D 0}}= & \frac{1}{2} \times\left[1-x-\frac{1}{K_{C} C_{D 0}}\right. \\
& \left.+\sqrt{(x-1)^{2}+\frac{2(x+1)}{K_{C} C_{D 0}}+\frac{1}{\left(K_{C} C_{D 0}\right)^{2}}}\right]
\end{aligned}
$$

Figure 5a shows an example of fitting procedure, while all obtained data are presented in Table 1. An initial inspection of the data in Table 1 seems to indicate that experimental $\mathrm{K}_{\mathrm{C}}$ values characterizing formation of triads vary showing a noticeable dependence on some reasons (dimer type, ligand structure, solubility, etc.). Below we provide a brief analysis of these findings.

Complexation abilities of dimers upon triad formation. The data listed in Table 1 have supplied us with the following main results. For all meso-pyridyl substituted extra-ligands, three Zn-porphyrin dimers with a rigid spacer $\left[(\mathrm{ZnOEP})_{2} \mathrm{Ph},(\mathrm{ZnHTPP})_{2}\right.$ and $\left.(\mathrm{ZnTPP})_{2}\right]$ are characterized by higher constants $\mathrm{K}_{\mathrm{C}}$ compared to those found for dimers with a flexible $-\mathrm{CH}_{2}-\mathrm{CH}_{2}-$ spacer $\left[(\mathrm{ZnOEChl})_{2}\right.$ and $\left.(\mathrm{ZnOEP})_{2}\right]$. Notably, $\mathrm{K}_{\mathrm{C}}$ values for triads containing dimers with a phenyl spacer are by two or three orders of magnitude larger than those for the binding of Zn-porphyrins [61, 66] and their dimers [41] with pyridine and related ligands. On the other hand, these values are close to complexation constants measured for complexes of Zn-porphyrin dimer with two pyridine-linked quinone dipyridyl-substituted porphyrins $\left(\mathrm{K}_{\mathrm{C}}=1.1 \times 10^{7} \mathrm{M}^{-1}\right.$ [80]) and for two-fold coordinated complexes of $\mathrm{Zn}_{2}$ gable porphyrins with $N, N^{\prime}$-diimidazolylmethane or $\gamma, \gamma^{\prime}$-dipyridylmethane, respectively [81]). Additionally, $(\mathrm{ZnHTPP})_{2}$ and $(\mathrm{ZnOEP})_{2} \mathrm{Ph}$ are complexed almost completely at molar ratio $x=\mathrm{C}_{\mathrm{L}} / \mathrm{C}_{\mathrm{D} 0}=1$. These facts together with spectral titration data discussed above lead to the conclusion, that the triads are formed due to two-fold coordination of $\mathrm{Zn}$ ions of the dimers with nitrogen atoms of pyridyl-substituents of the free bases. The larger complexation constants for the coordination of the bidentate porphyrin extra-ligand to these dimers suggest that each complex consists of one dimer and one free base forming a triad of the macrocycles. Like the complexes described in references [80, 81], the triads based on dipyridyl-substituted porphyrin free bases and $(\mathrm{ZnHTPP})_{2},(\mathrm{ZnTPP})_{2}$ or $(\mathrm{ZnOEP})_{2} \mathrm{Ph}$ are characterized by strong allosteric behavior showing that the first binding accelerates the second binding because of the chelate effect. In addition, values of activation energy measured for these triads $\left(E_{a}=0.7-0.8 \mathrm{eV}\right.$, evaluation method is shown in Fig. 5b) are very close to each other which demonstrates a key role of two-point coordination in the temperature stability of the complexes.

It should be noted that multipoint extra-ligation shows an interesting manner of molecular recognition and self-assembling. For instance, the cyclic aggregates of $\mathrm{Zn}$-porphyrins bearing a pyridyl group in mesoposition formed selectively, with high complexation constants owing to the high preorganization of the interacting components: $10^{8} \mathrm{M}^{-1}$ for the dimer, $5 \times 10^{12}$ $\mathrm{M}^{-2}$ for the trimer, and $>10^{12} \mathrm{M}^{-3}$ for the tetramer [63]. Large complexation constants $\left(\mathrm{K}_{\mathrm{C}}>10^{9} \mathrm{M}^{-1}\right)$ have been obtained also for three-point interaction of $\mathrm{Zn}$-porphyrins with 2,4,6-tri-(4-pyridyl)-s-triazine leading to the cyclic trimer formation [82].

It is evident from Table 1 that the binding constant of a given dimer to various ligands is the result of the 


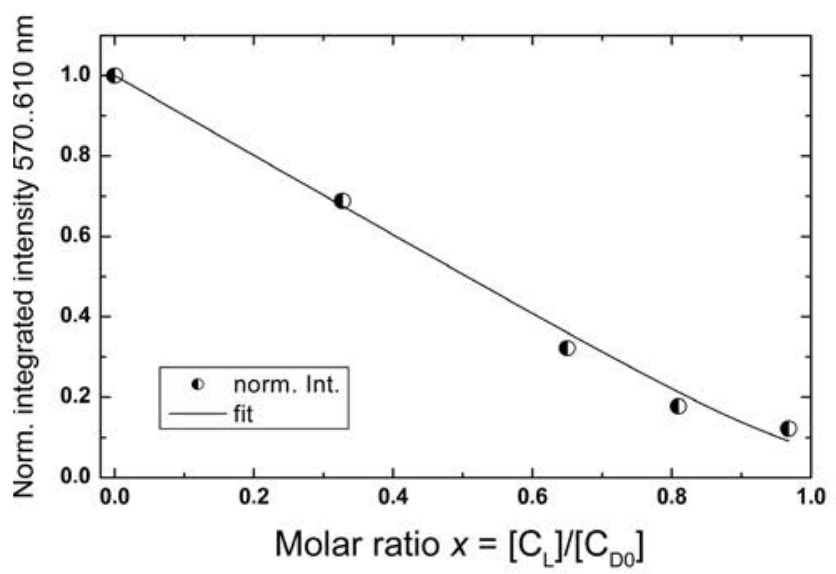

(a)

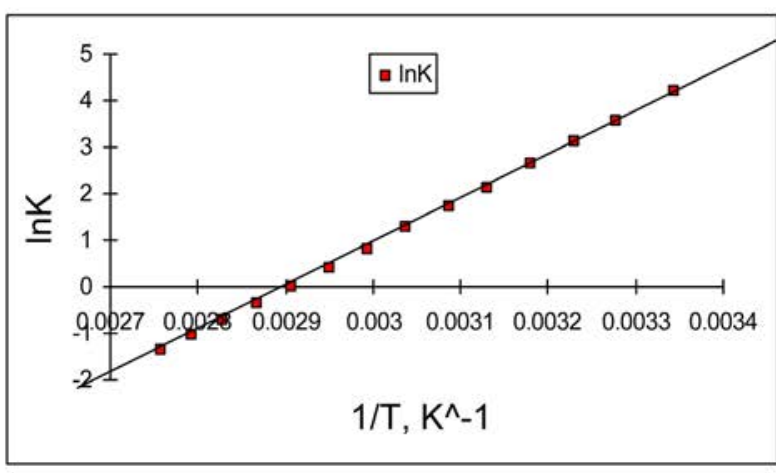

(b)

Fig. 5. Titration of the dimer $(\mathrm{ZnOEP})_{2} \mathrm{Ph}$ solution by porphyrin extra-ligand $\mathrm{H}_{2} \mathrm{P}\left(\mathrm{m}^{\wedge} \mathrm{Pyr}\right)_{2}-(\text { iso- } \mathrm{PrPh})_{2}$ in toluene at $293 \mathrm{~K}(\mathrm{a})$ : Dependence of the normalized integrated intensities of the uncomplexed dimer $v$ s. molar ratio $x=\mathrm{C}_{\mathrm{L}} / \mathrm{C}_{\mathrm{D} 0}$ fitted by Equation $7 . \mathrm{C}_{\mathrm{D} 0}=$ $2.5 \times 10^{-6} \mathrm{M}$, calculated value $\mathrm{K}_{\mathrm{C}}=(1.7 \pm 0.5) \times 10^{7} \mathrm{M}^{-1}$ at $\mathrm{Chi}^{\wedge} 2=0.00093$. (b): Dependence of the complexation constant $\mathrm{K}_{\mathrm{C}}$ ( $\mathrm{Y}$ axis, logarithmic scale) on temperature fitted by Arhenius law in a temperature range of 140-360 K

Table 1. Complexation constants for various triads formed by two-fold co-ordination of Zn-porphyrin dimers with tetrapyrrolic extra-ligands (based on absorption and fluorescence data upon titration experiments)

\begin{tabular}{|c|c|c|c|c|c|c|}
\hline \multirow[t]{2}{*}{ Triad composition } & \multirow[t]{2}{*}{ Solvent } & \multirow[t]{2}{*}{$\mathrm{K}_{\mathrm{C}}, 10^{6} \mathrm{M}^{-1}$} & \multicolumn{2}{|c|}{ Free components } & \multicolumn{2}{|c|}{ Complex } \\
\hline & & & $\mathrm{N}-\mathrm{N} l, \AA$ & $\mathrm{Zn}-\mathrm{Zn} \mathrm{d}, \AA$ & $\mathrm{N}-\mathrm{N} l, \AA$ & $\mathrm{Zn}-\mathrm{Zn} \mathrm{d}, \AA$ \\
\hline$(\mathrm{ZnOEP})_{2} \mathrm{Ph} \otimes \mathrm{H}_{2} \mathrm{P}\left(\mathrm{m}^{\wedge} \mathrm{Pyr}\right)_{2}$-(iso- $\left.\mathrm{PrPh}\right)_{2}$ & Tol & 17.2 & 9.908 & 12.907 & 10.330 & 12.131 \\
\hline$(\mathrm{ZnOEP})_{2} \mathrm{Ph} \otimes \mathrm{H}_{2} \mathrm{P}\left(\mathrm{m}^{\wedge} \mathrm{Pyr}\right)_{2}-(\text { iso- } \mathrm{PrPh})_{2}$ & $\mathrm{Tol}+\mathrm{CH}$ & 14.0 & 9.908 & 12.907 & 10.330 & 12.131 \\
\hline$(\mathrm{ZnOEP})_{2} \mathrm{Ph} \otimes \mathrm{H}_{2} \mathrm{P}\left(\mathrm{p}^{\wedge} \mathrm{Pyr}\right)_{2}$ & Tol & 5.0 & 10.978 & 12.907 & 10.440 & 12.197 \\
\hline$(\mathrm{ZnOEP})_{2} \mathrm{Ph} \otimes \mathrm{H}_{2} \mathrm{P}(\mathrm{m}-\mathrm{Pyr})_{2}-(\text { iso- } \mathrm{PrPh})_{2}$ & $\mathrm{Tol}+\mathrm{CH}$ & 10.1 & 14.075 & 12.907 & 12.571 & 12.881 \\
\hline$(\mathrm{ZnOEP})_{2} \mathrm{Ph} \otimes \mathrm{H}_{2} \mathrm{P}(\mathrm{m}-\mathrm{Pyr})_{2}-(\text { iso- } \mathrm{PrPh})_{2}$ & $\mathrm{MCH}$ & 13.0 & 14.075 & 12.907 & 12.571 & 12.881 \\
\hline$(\mathrm{ZnOEP})_{2} \mathrm{Ph} \otimes \mathrm{H}_{2} \mathrm{P}(\mathrm{m}-\mathrm{Pyr})_{2}-(\text { iso- } \mathrm{PrPh})_{2}$ & Tol & 1.06 & 14.075 & 12.907 & 12.571 & 12.881 \\
\hline$(\mathrm{ZnOEP})_{2} \mathrm{Ph} \otimes \mathrm{H}_{2} \mathrm{P}(\mathrm{m}-\mathrm{Pyr})_{2}$ & Tol & 5.8 & 14.075 & 12.907 & 12.571 & 12.881 \\
\hline$(\mathrm{ZnOEP})_{2} \mathrm{Ph} \otimes \mathrm{H}_{2} \mathrm{Chl}(\mathrm{m}-\mathrm{Pyr})_{2}$ & Tol & 1.7 & - & 12.907 & - & - \\
\hline$(\mathrm{ZnOEP})_{2} \mathrm{Ph} \otimes \mathrm{H}_{2} \mathrm{THP}(\mathrm{m}-\mathrm{Pyr})_{2}$ & Tol & 2.8 & - & 12.907 & - & - \\
\hline$(\mathrm{ZnTPP})_{2} \otimes \mathrm{H}_{2} \mathrm{P}\left(\mathrm{m}^{\wedge} \mathrm{Pyr}\right)_{2}$-(iso-PrPh $)_{2}$ & $\mathrm{Tol}+\mathrm{CH}$ & 0.78 & 9.908 & 12.724 & 10.366 & 12.111 \\
\hline$(\mathrm{ZnTPP})_{2} \otimes \mathrm{H}_{2} \mathrm{P}(\mathrm{m}-\mathrm{Pyr})_{2}$ & $\mathrm{CH}$ & 70.0 & 14.075 & 12.724 & 12.446 & 12.712 \\
\hline$(\mathrm{ZnOEChl})_{2} \otimes \mathrm{H}_{2} \mathrm{P}(\mathrm{m}-\mathrm{Pyr})_{2}$ & $\mathrm{MCH}$ & $\sim 0.6$ & 14.075 & 10.611 & - & - \\
\hline$(\mathrm{ZnOEP})_{2} \otimes \mathrm{H}_{2} \mathrm{P}(\mathrm{m}-\mathrm{Pyr})_{2}$ & $\mathrm{Tol}+\mathrm{CH}$ & $<0.02$ & 14.075 & - & - & - \\
\hline$(\mathrm{ZnHTPP})_{2} \otimes \mathrm{H}_{2} \mathrm{P}(\mathrm{m}-\mathrm{Pyr})_{2}$ & $\mathrm{MCH}$ & 6.5 & 14.075 & 12.724 & 12.446 & 12.712 \\
\hline$(\mathrm{ZnHTPP})_{2} \otimes \mathrm{H}_{2} \mathrm{Chl}(\mathrm{m}-\mathrm{Pyr})_{2}$ & $\mathrm{MCH}$ & 9.0 & - & 12.724 & - & - \\
\hline$(\mathrm{ZnHTPP})_{2} \otimes \mathrm{H}_{2} \mathrm{THP}(\mathrm{m}-\mathrm{Pyr})_{2}$ & $\mathrm{MCH}$ & 50.0 & - & 12.724 & - & - \\
\hline$(\mathrm{ZnHTPP})_{2} \otimes \mathrm{H}_{2} \mathrm{P}\left(\mathrm{m}^{\wedge} \mathrm{Pyr}\right)_{2}$ & $\mathrm{MCH}$ & 5.0 & 9.908 & 12.724 & 10.366 & 12.111 \\
\hline$(\mathrm{ZnHTPP})_{2} \otimes \mathrm{H}_{2} \mathrm{P}\left(\mathrm{p}^{\wedge} \mathrm{Pyr}\right)_{2}$ & $\mathrm{MCH}$ & 24.0 & 10.978 & 12.724 & 10.562 & 12.245 \\
\hline$(\mathrm{ZnHTPP})_{2} \otimes \mathrm{H}_{2} \mathrm{P}\left(\mathrm{m}^{\wedge} \mathrm{Pyr}\right)_{2}$-(iso-PrPh $)_{2}$ & $\mathrm{Tol}+\mathrm{CH}$ & 2.0 & 9.908 & 12.724 & 10.366 & 12.111 \\
\hline$(\mathrm{ZnHTPP})_{2} \otimes \mathrm{H}_{2} \mathrm{P}\left(\mathrm{m}^{\wedge} \mathrm{Pyr}\right)_{2}$-(iso-PrPh $)_{2}$ & $\mathrm{MCH}$ & 2.4 & 9.908 & 12.724 & 10.366 & 12.111 \\
\hline
\end{tabular}

Notes: symbol $\otimes$ shows what components are coupled in the complex. In addition, porphyrins with iso-propyl-phenyl side chains (iso- $\mathrm{PrPh})_{2}$ were used to modify steric interactions with TOPO molecules as well as improving $\mathrm{H}_{2} \mathrm{P}$ solubility. The solvents being used are as follows: toluene $(\mathrm{Tol})$, cyclohexane $(\mathrm{CH})$, methylcyclohexane $(\mathrm{MCH})$, and Tol $+\mathrm{CH}$ solvent $(1: 6)$ mixture. N-N $(l)$ and $\mathrm{Zn}-\mathrm{Zn}$ distances (d) are presented being estimated for individual compounds and in the triads (for optimized geometry, based on HyperChem 7.0, method PM3 calculations). 
interplay of few factors. Firstly, the conformation mobility of Zn-containing tetrapyrrole macrocycles in the dimers depends on the spacer properties (mesophenyl ring or $-\mathrm{CH}_{2}-\mathrm{CH}_{2}-$ bridge for chemical dimers, see Fig. 1), as well as on sterical interactions between spacer and neighboring side substituents of tetrapyrrole macrocycles. It may lead to various conformations of the dimer structure having different complexation abilities for the two-fold interactions with ligands. This situation will be discussed for all dimers being studied below. Secondly, data presented in Table 1 show that $\mathrm{N}-\mathrm{N}$ distances (abbreviated as $l$, see example in Fig. 1 for $\mathrm{H}_{2} \mathrm{P}$ $\left(\mathrm{m}^{\wedge} \mathrm{Pyr}\right)_{2}$ molecule $)$ in various ligands with $\left(\mathrm{m}^{\wedge} \mathrm{Pyr}\right)_{2}$, $(\mathrm{m}-\mathrm{Pyr})_{2}$ and $\left(\mathrm{p}^{\wedge} \mathrm{Pyr}\right)_{2}$ substitution do not strictly coincide with intercenter $\mathrm{Zn}-\mathrm{Zn}$ distances (abbreviated as d, see example in Fig. 1 for $\left.(\mathrm{ZnOEP})_{2} \mathrm{Ph}\right)$ in the dimers both for individual compounds and in the triads. Thus, the above matching conditions defined by differences in $l(\mathrm{~N}-\mathrm{N})$ and $\mathrm{d}(\mathrm{Zn}-\mathrm{Zn})$ distances may also influence on the efficiency of the triad formation. These effects will be discussed for various ligands in separate section later.

Really, for the individual dimer (ZnTPP) $)_{2}$ with the meso-phenyl bridge there exist two energetically favored conformations: one with coplanar porphyrin macrocycles and one with them tilted at $110^{\circ}$ [83]. In contrast, in the dimer $(\mathrm{ZnOEP})_{2} \mathrm{Ph}$ the ethyl groups restrict the phenyl bridge to a position orthogonal to the porphyrin planes, thus allowing for a coplanar structure only [84]. Almost equal abilities of $(\mathrm{ZnHTPP})_{2}$ and $(\mathrm{ZnOEP})_{2} \mathrm{Ph}$ to form various complexes imply that the conformational dynamics of the dimers does not play an essential role in their interaction with coordinating extra-ligands. In both theses triads the macrocycles of the dimer subunits are presumably coplanar. Thus, the above mentioned conformational freedom of $(\mathrm{ZnHTPP})_{2}$ is restricted upon ligation while that of $(\mathrm{ZnOEP})_{2} \mathrm{Ph}$ remains unchanged.

Transition to the dimer $(\mathrm{ZnOEP})_{2}$, with a flexible $-\mathrm{CH}_{2}-$ $\mathrm{CH}_{2}$ - spacer between the $\mathrm{ZnOEP}$ monomer moieties leads to a substantial reduction in the complexation ability $\left(\mathrm{K}_{\mathrm{C}}\right.$ value is estimated to be lower than $2 \times 10^{4} \mathrm{M}^{-1}$ ). The case of $(\mathrm{ZnOEChl})_{2}$ may be considered as an intermediate situation between $(\mathrm{ZnOEP})_{2} \mathrm{Ph}$ and $(\mathrm{ZnOEP})_{2}$. The complexation constant in this case is estimated to be $6 \times$ $10^{5} \mathrm{M}^{-1}$ assuming that the dimer fluorescence is strongly quenched in the triad. The reduced ability of these dimers to form triads with $\mathrm{H}_{2} \mathrm{P}-(\mathrm{m}-\mathrm{Pyr})_{2}$ can be well understood from the geometry and conformational mobility of dimers with phenyl and $-\mathrm{CH}_{2}-\mathrm{CH}_{2}-$ spacers. More specifically, in case of the dimers with $-\mathrm{CH}_{2}-\mathrm{CH}_{2}-$ spacer there is much more conformational flexibility. According to NMR ${ }^{1} \mathrm{H}$ data [85] ethane-bisporphyrins with a single $-\mathrm{CH}_{2}-\mathrm{CH}_{2}-$ bond via meso-positions (e.g. $\left.(\mathrm{ZnOEP})_{2}\right)$ have a wide set of conformations (from fully eclipsed at ambient temperature to fully staggered at $77 \mathrm{~K}$, see Scheme 1) due to rotation around the spacer. Thus, the probability of the fully staggered conformation providing the best conditions for two-point coordination, in which the $-\mathrm{CH}_{2}-\mathrm{CH}_{2}-$ spacer is in all-trans form, is relatively low at $293 \mathrm{~K}$. However, for $(\mathrm{ZnOEChl})_{2}$ the fully staggered conformation is favored since hydrogenated rings of the chlorin subunits of the dimer hinder other conformations. Hence, upon complexation with the extra-ligand, when the coordination hinders sterically all conformations except the fully staggered one, a change of conformational dynamics in $(\mathrm{ZnOEP})_{2}$ should be larger than that of $(\mathrm{ZnOEChl})_{2}$. On this basis, the favored coplanar arrangement of porphyrin subunits in the phenyl-bridged dimers (the intercenter $\mathrm{Zn}-\mathrm{Zn}$ distance $\mathrm{d}=12.7-12.9 \AA$ ) is more suitable for the formation of the two-fold coordinated complex with $\mathrm{H}_{2} \mathrm{P}-(\mathrm{m}-\mathrm{Pyr})_{2}(l=$ $14.07 \AA$ ) in comparison with the non-coplanar structure in the $-\mathrm{CH}_{2}-\mathrm{CH}_{2}-$ bridged dimers (even in the fully staggered conformation with $\mathrm{d}=10.6 \AA$ ). The lower ability of $(\mathrm{ZnOEP})_{2}$ to form complexes with $\mathrm{H}_{2} \mathrm{P}-(\mathrm{m}-\mathrm{Pyr})_{2}$ in comparison with that of $(\mathrm{ZnOEChl})_{2}$ can be caused by the higher conformational mobility of the former.

Complexation abilities of extra-ligands upon triad formation. Thermodynamic evidence also indicates that in addition to some features mentioned above for the dimers, certain effects are characteristic for various extra-ligands being used. Comparing the complexation ability of $(\mathrm{ZnHTPP})_{2}$ with porphyrin $\mathrm{H}_{2} \mathrm{P}-(\mathrm{m}-\mathrm{Pyr})_{2}$,
Fully eclipsed conformation: Ambient $\mathrm{T}$ $\mathrm{d}(\mathrm{Zn}-\mathrm{Zn})=5.5 \AA$

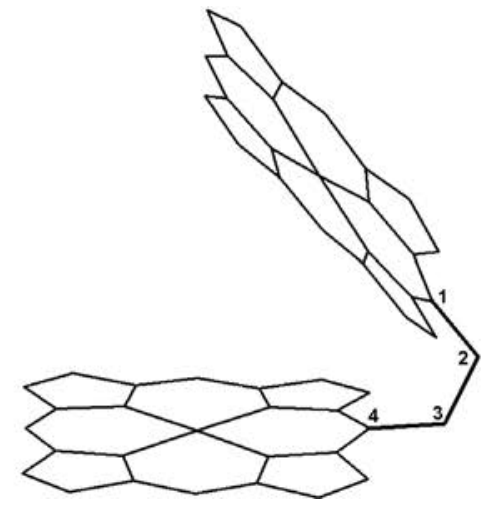

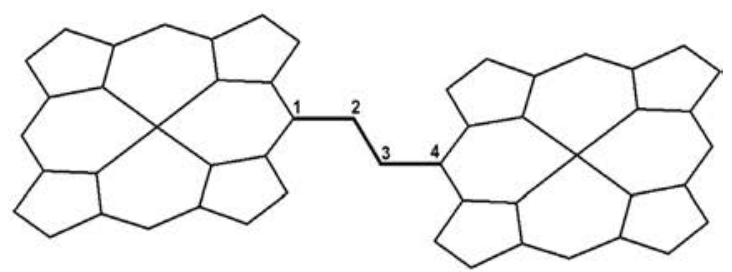

Fully staggered conformation: Low T d $(\mathrm{Zn}-\mathrm{Zn})=10.6 \AA$

Scheme 1. 
chlorin $\mathrm{H}_{2}$ Chl-(m-Pyr $)_{2}$ and tetrahydroporphyrin $\mathrm{H}_{2} \mathrm{THP}-$ $(\mathrm{m}-\mathrm{Pyr})_{2}$ in $\mathrm{MCH}$ at ambient temperature, there is a certain tendency of increase in complexation constant $\mathrm{K}_{\mathrm{C}}=(0.6 \rightarrow 0.9 \rightarrow 5.0) \times 10^{7} \mathrm{M}^{-1}$ over this series of extra-ligands of different nature but having the same pyridyl rings. It is known [86] that in chlorins (and in tetrahydroporphyrins as well) the electron density on the meso-positions of the methine bridges in the vicinity of the hydrated pyrrole ring is higher than in the corresponding porphyrins. Since the pyridyl substituents are attached to the meso-positions, an increase of the "electron donating ability" of the pyridyl nitrogen and, in turn, its ability to coordinate $\mathrm{Zn}$ ions of the dimer subunit is most likely to occur. Thus, the complexation constant of the complexes under investigation should grow from $\mathrm{H}_{2} \mathrm{P}-(\mathrm{m}-\mathrm{Pyr})_{2}$ to $\mathrm{H}_{2} \mathrm{Chl}-(\mathrm{m}-\mathrm{Pyr})_{2}$ and to $\mathrm{H}_{2} \mathrm{THP}-(\mathrm{m}-\mathrm{Pyr})_{2}$ which agrees with the experimental results. In this respect it should be mentioned that an additional reason leading to the observed difference in $\mathrm{K}_{\mathrm{C}}$ values for the above ligands might arise from changes in the conformation flexibility of the reduced porphyrin ring systems.

Our results indicate that the triad $(\mathrm{ZnHTPP})_{2} \otimes \mathrm{H}_{2} \mathrm{P}-$ $\left(\mathrm{p}^{\wedge} \mathrm{Pyr}\right)_{2}$ (I) has an essentially different structure compared to the triad $(\mathrm{ZnHTPP})_{2} \otimes \mathrm{H}_{2} \mathrm{P}-(\mathrm{m}-\mathrm{Pyr})_{2}$ (III) (see Fig. 2). In fact, in the case of $\mathrm{H}_{2} \mathrm{P}-\left(\mathrm{p}^{\wedge} \mathrm{Pyr}\right)_{2}$ ligand the geometry of the pyridyl substitution $(l=11 \AA)$ provides better matching for two-fold coordination with $(\mathrm{ZnHTPP})_{2}$ or $(\mathrm{ZnOEP})_{2} \mathrm{Ph}(\mathrm{d}=12.9 \AA)$ in comparison with that for $\mathrm{H}_{2} \mathrm{P}-(\mathrm{m}-\mathrm{Pyr})_{2}$ ligand $(l=14.1 \AA)$. Another feature of the triads $(\mathrm{ZnHTPP})_{2} \otimes \mathrm{H}_{2} \mathrm{P}-\left(\mathrm{p}^{\wedge} \mathrm{Pyr}\right)_{2}$ and $(\mathrm{ZnOEP})_{2} \mathrm{Ph} \otimes \mathrm{H}_{2} \mathrm{P}\left(\mathrm{p}^{\wedge} \mathrm{Pyr}\right)_{2}$ is that the lone pair electron orbitals of $\mathrm{N}$ atoms, that participate in the coordination with $\mathrm{Zn}$ ions of the dimers, form an angle of $90^{\circ}$ with respect to the dimer plane. These facts provide clear explanation of higher $\mathrm{K}_{\mathrm{C}}$ values for the triads $(\mathrm{ZnHTPP})_{2} \otimes \mathrm{H}_{2} \mathrm{P}-\left(\mathrm{p}^{\wedge} \mathrm{Pyr}\right)_{2}$ in comparison with triads $(\mathrm{ZnHTPP})_{2} \otimes \mathrm{H}_{2} \mathrm{P}-(\mathrm{m}-\mathrm{Pyr})_{2}$ and $(\mathrm{ZnOEP})_{2} \mathrm{Ph} \otimes \mathrm{H}_{2} \mathrm{P}(\mathrm{m}-\mathrm{Pyr})_{2}$-(iso- $\left.\mathrm{PrPh}\right)_{2}$.

Finally, we call attention to variations of the complexation ability for the triad formation upon the solvent changing (Table 1). For the same triad, this is reflected as a rule by the increase of $\mathrm{K}_{\mathrm{C}}$ values when going from toluene to toluene + cyclohexane mixture or to pure cyclohexane and methylcyclohexane. As was mentioned long ago [71], this effect may be explained by different solubility of tetrapyrrole compounds in solvents under consideration. Being smaller in cyclohexane and methylcyclohexane compared to toluene, it may manifest itself in the relative increase of complexation interactions leading to the triad formation. From Table 1 it is seen that this is also the case for the complexation of the dimers with $\mathrm{H}_{2} \mathrm{P}(\mathrm{m}-\mathrm{Pyr})_{2}$ or $\mathrm{H}_{2} \mathrm{P}\left(\mathrm{m}^{\wedge} \mathrm{Pyr}\right)_{2}$ in comparison with $\mathrm{H}_{2} \mathrm{P}(\mathrm{m}-\mathrm{Pyr})_{2}$-(iso- $\left.\mathrm{PrPh}\right)_{2}$ or $\mathrm{H}_{2} \mathrm{P}\left(\mathrm{m}^{\wedge} \mathrm{Pyr}\right)_{2}$-(iso- $\left.\mathrm{PrPh}\right)_{2}$, as far as more spacious isopropyl-phenyl substituted pyridyl porphyrins are better soluble than pyridyl substituted macrocycles. At last, it should be mentioned that upon temperature lowering down to $77 \mathrm{~K}$ chemical dimers $(\mathrm{ZnOEP})_{2} \mathrm{Ph}$ and trimers $(\mathrm{ZnOEP})_{3} \mathrm{Ph}_{2}$ are capable to form self-assembled structures with even one pyridyl containing ligand, $\mathrm{CuP}-(\mathrm{p}-\mathrm{Pyr})_{1}(\mathrm{Ph})_{3}$ [44] due to an increased $\mathrm{K}_{\mathrm{C}}$ value for one-point interaction in these conditions.

\section{Nanoassemblies based on semiconductor quantum dots and porphyrin ligands}

The above results allowed us to use the discussed ideas for the non-covalent binding of "QD-porphyrin" nanoassemblies. In the case of $\mathrm{CdSe} / \mathrm{ZnS}$ QDs, coordination interactions may be realized via $\mathrm{Zn}$ ions of $\mathrm{ZnS}$ shell and appropriate anchoring groups of functionalized organic molecules (ligands). At the same time, some specific aspects should be taken into account for "QD-porphyrin" nanoassemblies. Because of the increased surface-to-volume ratio relative to bulk materials, QD surface are subject to chemical and structural disorder. Indeed, for QD of about $\mathrm{d}_{\mathrm{CdSe}}=3 \mathrm{~nm}$, the portion of the surface atoms is about $50 \%$, and the importance of the surface for QDs is obvious. Correspondingly, colloidal QDs in solution are subject to various dynamic processes which are related to QD interface properties that affect QD photoluminescence (PL) properties. To name a few, this can be the attachment and detachment of protective ligands (e.g. TOPO, amines, etc.) [87-89], the participation of QDs in hybrid nanoassemblies with functionalized organic molecules [90-93] or with even biostructures [94]. Really, the formation process of hybrid nanoassemblies takes place in competition with capping ligand dynamics (ligand exchange dynamics). Further, the QD surface is far from being totally covered with capping ligand molecules, and the dynamics of the QD interaction with functionalized organic molecules (such as porphyrins) may be rather complex including at least the variation of number of organic molecules on QD surface and their complexation abilities. Besides fundamental aspect of such interactions, knowledge of the ligand dynamics and surface functionalization can play an important role in various technological fields, e.g. for the fabrication of nanostructured inks for solutionprocessed photovoltaics [95] or printed semiconductor layers in flexible electronics [96].

Proof of "QD-porphyrin” nanoassembly formation. Typically, at ambient temperature, the titration of CdSe/ZnS QD solution by a comparable amount of meso-pyridyl substituted porphyrins $\mathrm{H}_{2} \mathrm{P}-(\mathrm{Pyr})_{\mathrm{n}}$ leads to the formation of quasi-stable "QD-porphyrin" nanoassemblies. The attachment of porphyrins to the QD surface manifests itself in the QD photoluminescence (PL) quenching (emission intensity decrease and decay shortening [39, 45, 46], Fig. 6). Based on detailed quantitative experimental and theoretical analysis of QD PL quenching effects in self-organized "QD-dye" nanoassemblies (including porphyrins [39, 45, 48] and perylene bisimides $[47,49,50])$ studied both in bulk solutions and on a single particle detection level, we have 


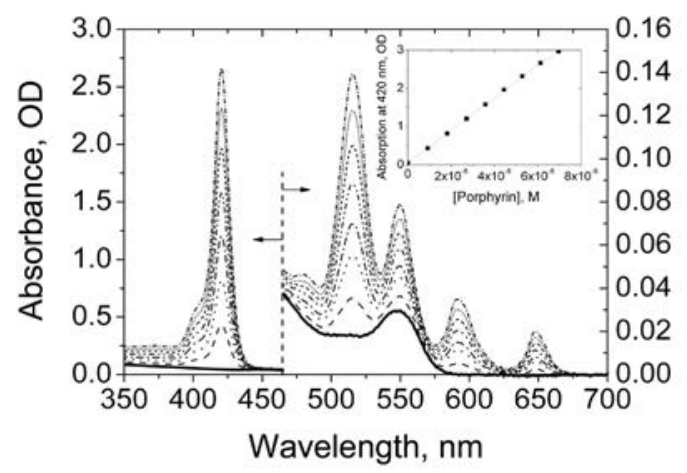

(a)

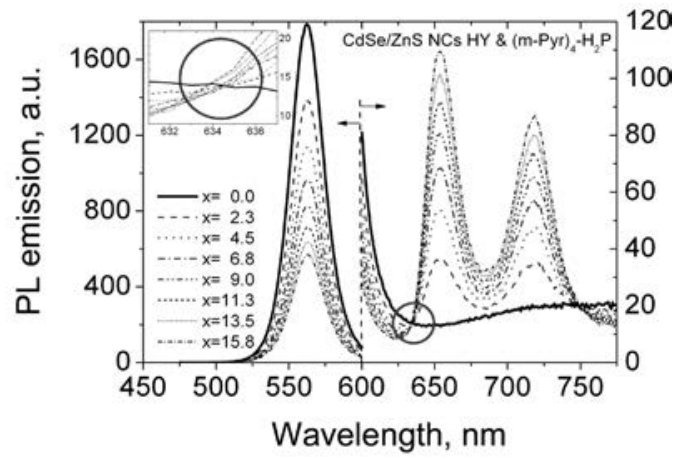

(b)

Fig. 6. Absorption (a) and emission (b, $\left.\lambda_{\mathrm{ex}}=465 \mathrm{~nm}\right)$ spectra of CdSe/ZnS QD $\left(\mathrm{d}_{\mathrm{CdSe}}=3.0 \mathrm{~nm}, 2 \mathrm{ZnS}\right.$ monolayers, $\mathrm{C}_{\mathrm{QD}}=4 \times 10^{-7}$ $\mathrm{M})$ and $\mathrm{H}_{2} \mathrm{P}(\mathrm{m}-\mathrm{Pyr})_{4}$ molecules upon molar ratio $x=\left[\mathrm{C}_{\mathrm{L}}\right] /\left[\mathrm{C}_{\mathrm{QD}}\right]$ increase. Inset in A: peak intensity of the Soret band as function of the nominal concentration. Deviations from linearity represent the uncertainty in the amount of added substance $($ i.e. $5.0 \pm 2.5 \%)$. Circle in (b) shows the existence of quasi-isosbestic point in emission spectra upon titration

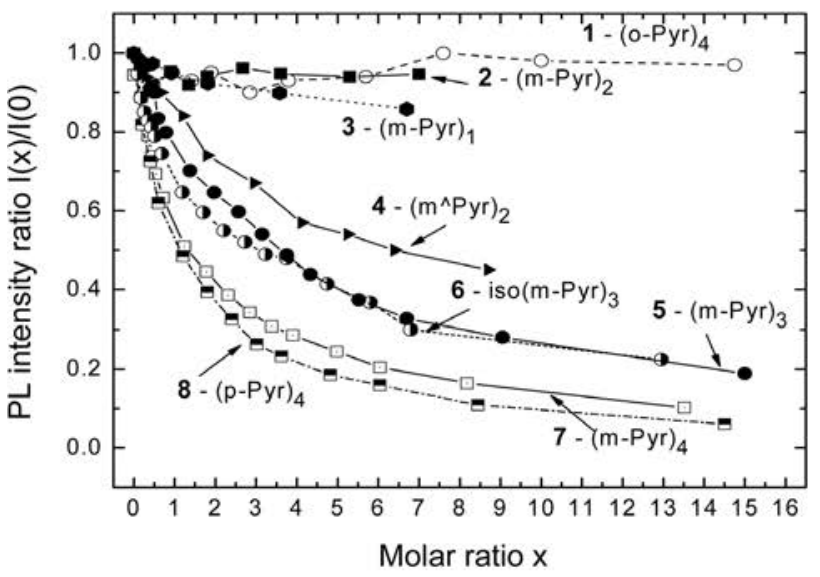

(a)

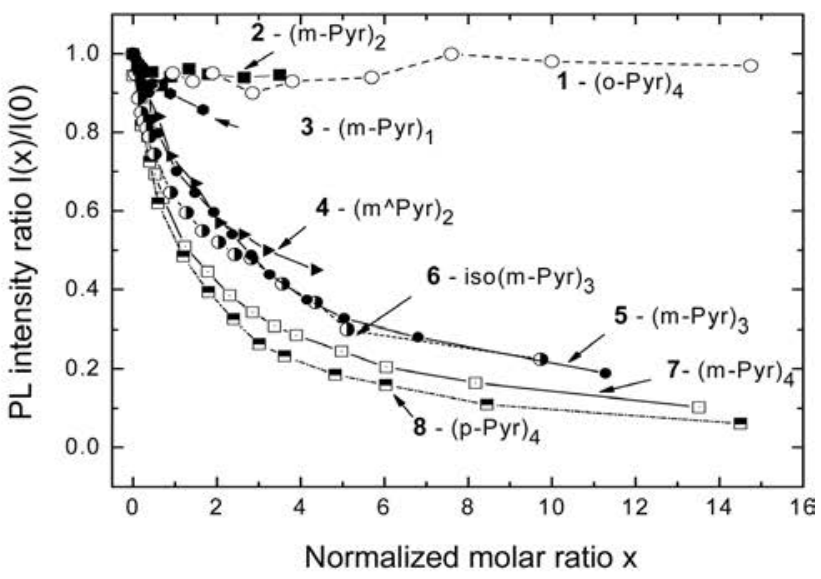

(b)

Fig. 7. QD relative PL intensity changes (quenching) $\mathrm{I}(x) / \mathrm{I}(0)$ as function of the molar ratio $x=\left[\mathrm{C}_{\mathrm{L}}\right] /\left[\mathrm{C}_{\mathrm{QD}}\right](\mathrm{a})$ and the normalized (to the number of pyridyl groups) molar ratio $x$ (b) for the same CdSe/ZnS QD $\left(\mathrm{d}_{\mathrm{CdSe}}=2.5 \mathrm{~nm}\right.$, number of ZnS monolayers $\mathrm{n}_{\mathrm{ZnS}}=$ $\left.2, \mathrm{C}_{\mathrm{QD}}=4 \times 10^{-7} \mathrm{M}\right)$ and various porphyrin molecules [45]: (1) $\mathrm{H}_{2} \mathrm{P}-(\mathrm{o}-\mathrm{Pyr})_{4}$; (2) $\mathrm{H}_{2} \mathrm{P}-(\mathrm{m}-\mathrm{Pyr})_{2}(\mathrm{Ph})_{2}$; (3) $\mathrm{H}_{2} \mathrm{P}-(\mathrm{m}-\mathrm{Pyr})_{1}$; (4) $\mathrm{H}_{2} \mathrm{P}-$ (m^Pyr) $)_{2}$; (5) $\mathrm{H}_{2} \mathrm{P}-(\mathrm{m}-\mathrm{Pyr})_{3}$; (6) $\mathrm{H}_{2} \mathrm{P}-(\mathrm{iso})-(\mathrm{m}-\mathrm{Pyr})_{3}$; (7) $\mathrm{H}_{2} \mathrm{P}-(\mathrm{m}-\mathrm{Pyr})_{4}$; (8) $\mathrm{H}_{2} \mathrm{P}-(\mathrm{p}-\mathrm{Pyr})_{4}$. In comparison with $\mathrm{H}_{2} \mathrm{P}-(\mathrm{m}-\mathrm{Pyr})_{3}$ (compound 5), the porphyrin ligand $\mathrm{H}_{2} \mathrm{P}$-(iso)-(m-Pyr) 3 (compound 6) has 3 isopropyl-phenyl-substituted pyridyl rings (shown in Fig. 1, part "meso-pyridyl substituted porphyrins") thus being more spacious and better soluble. Excitation was chosen at $\lambda_{\text {exc }}=465 \mathrm{~nm}$, where the molar decimal extinction coefficient of the added porphyrin ligand $\varepsilon_{\mathrm{L}}<<\varepsilon_{\mathrm{QD}}$, and experimental part of the ligand absorption did not exceed $5 \%$ of total OD values in the range $x=1-4$. Toluene, $295 \mathrm{~K}$

shown that this quenching is caused by two main reasons. One is well-known resonant energy transfer, FRET QD $\rightarrow$ dye molecule. The other one is the electron tunneling in the conditions of quantum confinement [45]. In the later case, upon interaction of meso-pyridyl substituted porphyrin molecule with QD surface, the QD electron wave function may be locally modified (via inductive and/or mesomeric effects [97]) forming a surface local state capable to trap the electron of the photogenerated exciton. Not wishing to detain the reader's attention to details of these processes (discussed in above cited references), in this section we aim at a comprehensive description of capping ligand and porphyrin molecules dynamics using QD PL quenching as indicator. Namely this dynamics is of crucial importance for photoinduced processes in "QD-porphyrin" nanoassemblies, with titration experiments as a step to an experimental investigation of the chemical topography.

With respect to porphyrin structure, the strategy was (see Fig. 1): (i) to vary the number of pyridyl-rings from 1 to 4 including opposite $\mathrm{H}_{2} \mathrm{P}-(\mathrm{m}-\mathrm{Pyr})_{2}$ and adjacent $\mathrm{H}_{2} \mathrm{P}$ $\left(m^{\wedge} \mathrm{Pyr}\right)_{2}$ variants, and (ii) to replace the type of nitrogen (N) position within the pyridyl ring from the meta- $(\mathrm{m})$, to ortho- (o), and para- (p) N position in the case of the 4-fold meso-pyridyl-substituted $\mathrm{H}_{2} \mathrm{P}$ molecules. The results depicted in Fig. 7a show that for the given CdSe/ ZnS QD under the same titration conditions, the observed QD PL quenching depends strongly on the number and 
type of pyridyl substituents: (i) $\mathrm{H}_{2} \mathrm{P}-(\mathrm{o}-\mathrm{Pyr})_{4}$ does almost not quench the PL; (ii) QD PL quenching is strongest for $\mathrm{H}_{2} \mathrm{P}-(\mathrm{p}-\mathrm{Pyr})_{4}$ and $\mathrm{H}_{2} \mathrm{P}-(\mathrm{m}-\mathrm{Pyr})_{4}$; (iii) within the $\mathrm{H}_{2} \mathrm{P}-(m-\mathrm{Pyr})_{\mathrm{n}}$ manifold there is a systematic increase of quenching efficiency upon sequential increase of $n=1 \div$ 4; (iv) $\mathrm{H}_{2} \mathrm{P}-(\mathrm{m}-\mathrm{Pyr})_{2}$ shows low $\mathrm{PL}$ quenching efficiency, like $\mathrm{H}_{2} \mathrm{P}-(\mathrm{m}-\mathrm{Pyr})_{1}$; (v) $\mathrm{H}_{2} \mathrm{P}-\left(m^{\wedge} \mathrm{Pyr}\right)_{2}$ is essentially stronger quencher compared to $\mathrm{H}_{2} \mathrm{P}-(\mathrm{m}-\mathrm{Pyr})_{2}$.

As shown in Fig. 7a, the QD PL quenching efficiency and thus the probability to form "QD-porphyrin" nanoassemblies is decreased with a decreasing number of pyridyl rings $(\mathrm{m}-\mathrm{Pyr})_{\mathrm{n}}$. Assuming that the probability of the nanoassembly formation is linearly proportional to the number of pyridyl rings, one can define an effective molar ratio $x_{\text {pyr }}=x(N / 4)$ that scales with $N$, where $N$ is the number of pyridyl rings for a given $\mathrm{H}_{2} \mathrm{P}$ molecule. Correspondingly, $x_{\mathrm{pyr}}$ becomes smaller with a decreasing number of pyridyl rings. Doing so, we obtain a rescaling of the QD PL quenching efficiency for every $\mathrm{H}_{2} \mathrm{P}$ molecule (depicted in Fig. 7b). In the result, all of the quenching curves besides those for $\mathrm{H}_{2} \mathrm{P}-(m-\mathrm{Pyr})_{1}, \mathrm{H}_{2} \mathrm{P}-(m-\mathrm{Pyr})_{2}(\mathrm{Ph})_{2}$ and $\mathrm{H}_{2} \mathrm{P}-(\mathrm{o}-\mathrm{Pyr})_{4}$ are shifted towards one single curve. The overall result is a kind of "master" curve for QD PL the quenching efficiency. In case that only one pyridyl ring can be anchored effectively, the agreement with the master curve becomes less satisfactory. It follows from this behavior, that the assumption relating the probability to form a "QD-porphyrin" nanoassembly with the number of pyridyl rings having access to the QD surfaces is correct. The stability of a two-point interaction will be at least a factor of 2 stronger than a one-point interaction, as can be deduced from the pronounced mismatch of the (scaled) one point interaction curves for $\mathrm{H}_{2} \mathrm{P}-(m-\mathrm{Pyr})_{1}$ and $\mathrm{H}_{2} \mathrm{P}-(m-\mathrm{Pyr})_{2}(\mathrm{Ph})_{2}$ as compared to the master curve. The importance of a two-point interaction has also been demonstrated for CdSe/ZnS QD-protein complexes [98]. The variation of the QD PL quenching efficiency with respect to the number, kind, and position of pyridyl rings in $\mathrm{H}_{2} \mathrm{P}$ molecules points toward a dynamic equilibrium between $\mathrm{QD}-\mathrm{H}_{2} \mathrm{P}$ nanoassemblies and free entities, as has also been observed for multiporphyrin arrays [17, $41,44,70,99,100]$. The equilibrium is dynamic, since assuming an infinitely strong coupling would not result in a dependence of the quenching on the number of pyridyl rings.

The above presented results lead to the conclusion that in "QD-porphyrin" nanoassemblies, $\mathrm{H}_{2} \mathrm{P}$ molecules anchor on the $\mathrm{CdSe} / \mathrm{ZnS}$ surface in a nearly perpendicular fashion with two nitrogen lone pair orbitals (at most) forming coordination bonds with the surface (see Fig. 3c). From geometric arguments, the QD PL weak quenching behavior observed for $\mathrm{H}_{2} \mathrm{P}-(m-\mathrm{Pyr})_{2}$ molecules with opposite pyridyl rings can thus be easily rationalized because a contact of opposite pyridyl rings to the surface is impossible due to geometric (steric) reasons in the case of a parallel orientation of the porphyrin macrocycle with respect to the QD surface. Theoretical simulations (ab initio DFT with the VASP code [64]) have shown also that for the optimized geometry of "QD-porphyrin" nanoassemblies, the mutual arrangement of $\mathrm{H}_{2} \mathrm{P}-(m-$ $\mathrm{Pyr}_{4}{ }_{4}$ molecules is perpendicular relative to QD surface (see Fig. 3d). It is seen from Fig. 3b that capping TOPO molecule has only one coordination bond via $\mathrm{O}$ atom for the QD surface attachment. Thus, considering space-filling molecular entities for "QD-porphyrin" nanoassemblies, in the case of competitive exchange of TOPO capping molecules by attaching porphyrin ligands possessing a two-point interaction, one $\mathrm{H}_{2} \mathrm{P}$ molecule may replace about 2-3 TOPO molecules or, alternatively, fills a free volume corresponding to 2-3 TOPO molecules.

Finally, as was outlined above, in bulk solutions the attachment of functionalized porphyrin molecules to a QD surface leads to a noticeable QD PL quenching due to FRET and non-radiative relaxation channels for the exciton. Interestingly, that QD PL quenching (as a manifestation of the "QD-porphyrin" nanoassembly formation) is also visible in experiments with single nanoobjects. Figure 8 shows the comparison of blinking statistics for two samples in spin-coated toluene solution at $295 \mathrm{~K}$ : single $\mathrm{CdSe} / \mathrm{ZnS}$ QDs and single "QD- $\mathrm{H}_{2} \mathrm{P}(\mathrm{m}-$ Pyr) ${ }_{4}$ " nanoassemblies both having the same initial QD concentration and being excited within the QD first excitonic absorption band. It is seen from Figs $8 \mathrm{~b}$ and $8 \mathrm{c}$ that for both cases blinking statistics show a power law distribution for "on-" and "off-" times. Dark QD states are usually explained by charged nanocrystals [101], and the heterogeneity (power law behavior [102]) is inherent to broadly distributed (de-)population processes of the dark state. In case of nanoassemblies, values for $\left\langle\mathrm{t}_{\text {on }}\right\rangle=$ $0.18 \mathrm{~s}$ do not change with respect to those measured for QD $\left(<\mathrm{t}_{\mathrm{on}}>=0.18 \mathrm{~s}\right)$, while a substantial increase of the "off"-times is observed for QD with attached porphyrin molecules ( $1.2 \mathrm{~s}$ in comparison to $0.75 \mathrm{~s}$ ). This elongation of dark periods is equivalent to PL quenching. These findings are considered as a proof of QD-porphyrin interactions leading to QD PL quenching also on a single assembly level. Additionally, a comparison of ensemble and single assembly experiments allows the unravelling of PL specific quenching mechanisms which are of importance for the identification of dynamic processes in QD-dye nanocomposites in general.

Estimations of complexation constants for " $Q D$-porphyrin" nanoassemblies. When numerically analysing QD PL quenching data for various porphyrin molecules in order to evaluate the corresponding complexation constants $\mathrm{K}_{\mathrm{C}}$ one should take into account few aspects: ligands exchange dynamics (depending on TOPO concentration and solvent properties) and number of $\mathrm{H}_{2} \mathrm{P}$ $(\mathrm{m}-\mathrm{Pyr})_{\mathrm{n}}$ molecules per QD. The determination of the number of porphyrin molecules per QD over the course of titration experiments is difficult, since the overall PL quenching depends both on the (a priori unknown) quenching efficiency and on the number of dye molecules on the QD surface. To separate these two effects, one 


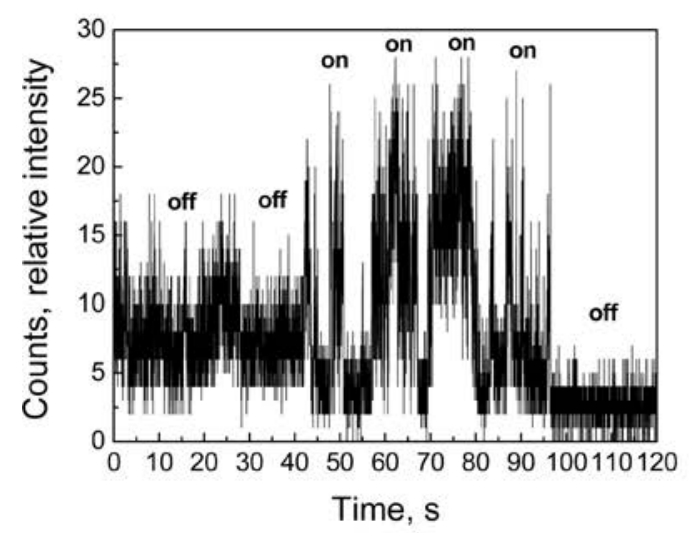

(a)

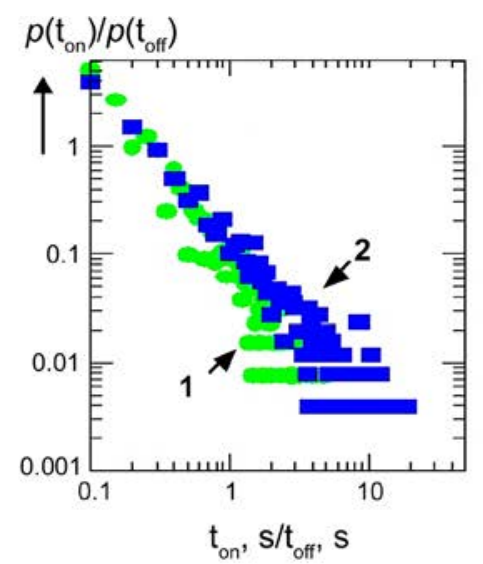

(b)

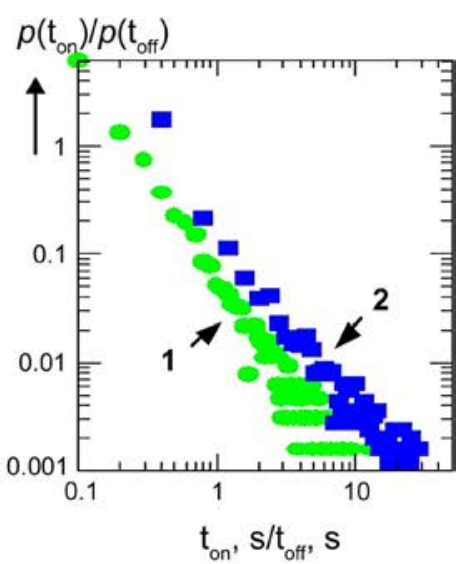

(c)

Fig. 8. "On" and "off" intensity fluctuations (a) and blinking statistics for single TOPO capped CdSe/ZnS QDs (b) and for single "QD- $\mathrm{H}_{2} \mathrm{P}(\mathrm{m}-\mathrm{Pyr})_{4}$ " nanoassemblies at molar ratio $x=10$ (c). QD parameters: $\mathrm{C}_{\mathrm{QD}}=1.8 \times 10^{-9} \mathrm{M}, \mathrm{d}_{\mathrm{CdSe}}=3.2 \mathrm{~nm}, \mathrm{n}_{\mathrm{ZnS}}=3 ;$ laser excitation at $\lambda_{\text {exc }}=514.5 \mathrm{~nm}, \mathrm{P}=250 \mu \mathrm{W}$. Samples have been prepared by spin coating from toluene solution onto quartz surface at $295 \mathrm{~K}$. Nanoassemblies were prepared at a molar ratio $x=\left[\mathrm{C}_{\mathrm{L}}\right] /\left[\mathrm{C}_{\mathrm{QD}}\right]=10$, at which the bulk QD PL quenching is about $40 \%$. The presented data were averaged for at least 20 individual objects from free and porphyrin-assembled QDs. Average "on-" (1) and "off"-times (2) are indicated in each graph

needs the independent identification of the number of attached porphyrin molecules merely from spectroscopic means. At first steps during the titration procedure upon "QD-porphyrin" nanoassembly formation, the spectra show that only a small part of $\mathrm{H}_{2} \mathrm{P}$ molecules added becomes attached to the QD surface, indicated by the missing of an isosbestic point [49]. On the other hand, for porphyrin molecules being attached on QD surface, spectral red shifts of both the Q- and Soret absorption bands as well as a blue shift of the fluorescence Q-band accompanied by a slight change in the Franck-Condon envelope of the overall spectrum are observed [45, 103]. These shifts and the slight inhomogeneous broadening of the porphyrin Soret band indicate that at low molar ratios $x \leq 1$ most of the $\mathrm{H}_{2} \mathrm{P}$ molecules are conjecturally included in "QD-porphyrin" nanoassemblies.

Without consideration of the dynamic equilibrium (which is the case at $x \leq 1$ ), it is reasonable to assume that the PL quenching rate for a given QD with $n$ attached chromophores is proportional to $\mathrm{n}$, whatever the quenching mechanism is. Like it has been done earlier [104] as well as and in recent publications [45, 93, 105], the formation of "QD-porphyrin" nanoassemblies may be described by a Poisson distribution;

$$
P(n)=X n \frac{\exp (-x)}{n !}
$$

where $x$ is the average number of chromophores per one QD (estimated from a molar ratio $\left(x=\left[\mathrm{C}_{\mathrm{L}}\right] /\left[\mathrm{C}_{\mathrm{QD}}\right]\right), \mathrm{n}$ is the number of attached chromophores on a given QD. Correspondingly, the QD PL intensity ratio $\mathrm{I}(x) / \mathrm{I}_{0}$ may be written as;

$$
\frac{\mathrm{I}(\mathrm{x})}{\mathrm{I}(0)}=\sum_{\mathrm{n}=0}^{\infty} \frac{\mathrm{k}_{\mathrm{D}}}{\mathrm{k}_{\mathrm{D}}+\mathrm{nk}_{\mathrm{Q}}} \mathrm{X}^{\mathrm{n}} \frac{\exp (-\mathrm{x})}{\mathrm{n} !}[45,103]
$$

where $\mathrm{k}_{\mathrm{D}}$ is the total intrinsic PL decay rate for alone QD and $\mathrm{k}_{\mathrm{Q}}$ the PL quenching rate for QD in "QD-porphyrin" nanoassemblies.

The experimental PL quenching data $\mathrm{I}(x) / \mathrm{I}(0)$ of Fig. $7 \mathrm{~b}$ presented as function of the rescaled molar ratio $x$ demonstrate that $\mathrm{n} \cdot \mathrm{k}_{\mathrm{Q}}$ is approximately the same for most of the "QD-porphyrin" nanoassemblies. This implies that all variants of $\mathrm{H}_{2} \mathrm{P}-(\mathrm{Pyr})_{\mathrm{n}}$ molecules exhibit the same quenching mechanism upon assembling on QD. The maximum number of anchored porphyrin molecules depends on several factors, such as the number and kinds of accessible sites ("empty places") on the QD surface which are not occupied by TOPO ligands, the competitive dynamic equilibrium between TOPO and $\mathrm{H}_{2} \mathrm{P}$ molecules depending on both complexation constants $\mathrm{K}_{\mathrm{C}}$ for TOPO and porphyrin molecules and their relative concentrations. It follows from detailed spectral observations $[49,103]$ that at low molar ratios $x$ all $\mathrm{H}_{2} \mathrm{P}-(\mathrm{Pyr})_{\mathrm{n}}$ molecules, especially $\mathrm{H}_{2} \mathrm{P}-(\mathrm{Pyr})_{4}$, are attached to the $\mathrm{CdSe} / \mathrm{ZnS}$ surface. Estimations according to Equation 8 show that at $x=1$, the related probabilities $\mathrm{P}_{\mathrm{i}}$ of the number of porphyrin molecules per $\mathrm{QD}$ are $\mathrm{P}_{0}=$ $0.3, \mathrm{P}_{1}=0.4, \mathrm{P}_{2}=0.3$, respectively.

Since the well defined QD PL quenching effects are even observed at molar ratios $x<1$ (see curves 7 and 8 in Fig. 7a), one can neglect (following statistical arguments) nanoassemblies with more than one $\mathrm{H}_{2} \mathrm{P}-(\mathrm{Pyr})_{\mathrm{n}}$ molecules per QD. Thus, at $x \leq 1$ the experimental titration data may be discussed on the basis of a bi-molecular reaction scheme valid for a dynamic equilibrium between selfassembled and free constituents as has been discussed in Section 3.1 for porphyrin triads. Correspondingly, on the basis of experimental QD PL quenching data at $x \leq 1$ for a given CdSe/ZnS QD (Fig. 7a) and Equations 6 and 7, it follows that the values of complexation constant $\mathrm{K}_{\mathrm{C}}$ are 


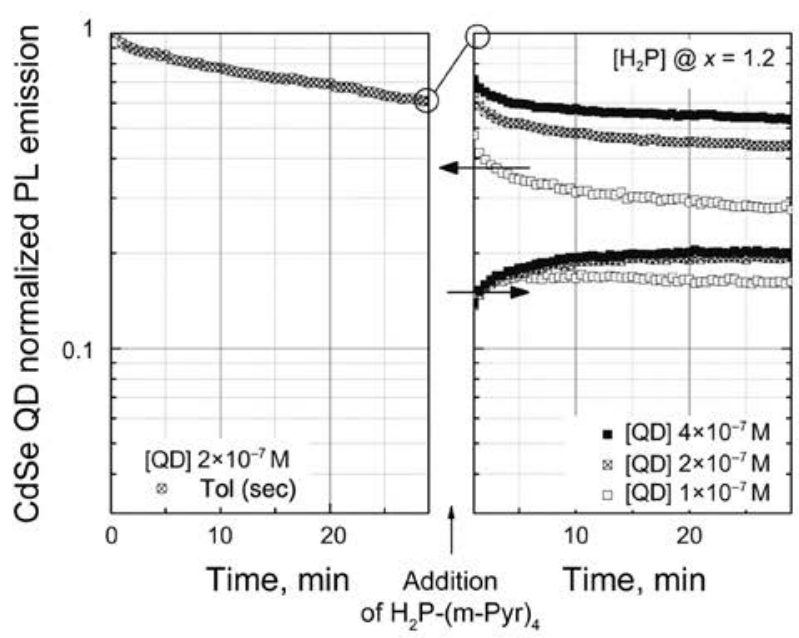

(a) (b)

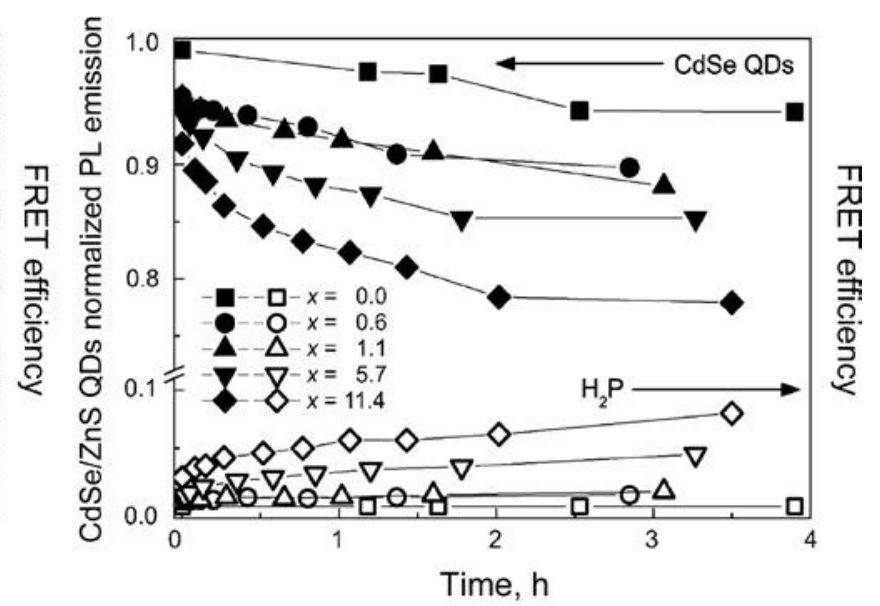

(c)

Fig. 9. Influence of sample conditions on the time dependent QD PL quenching and FRET efficiency (relative units) for "QD-porphyrin" nanoassemblies based on QDs and $\mathrm{H}_{2} \mathrm{P}-(\mathrm{m}-\mathrm{Pyr})_{4}$ molecules in toluene at $293 \mathrm{~K}$. For all dependences, left scale is QD normalized PL emission, right scale is experimental FRET efficiency QD $\rightarrow$ porphyrin calculated according to the procedure described earlier $[45,46,49]$. (a): Time dependent emission for alone CdSe QD $\left(\mathrm{d}_{\mathrm{CdSe}}=3.0 \mathrm{~nm},\left[\mathrm{C}_{\mathrm{QD}}\right]=2 \times 10^{-7} \mathrm{M}\right)$. $(\mathrm{b})$ : Time dependent emission for CdSe QD $\left(\mathrm{d}_{\mathrm{CdSe}}=3.0 \mathrm{~nm}\right)$ and FRET efficiencies for nanoassemblies at constant molar ratio $x=1.2$ for three initial QD concentrations. (c): Long-time dependence of the PL of CdSe/ZnS QDs ( $\mathrm{d}_{\mathrm{CdSe}}=3.0 \mathrm{~nm}, 2 \mathrm{ZnS}$ monolayers) and FRET efficiency for "QD-porphyrin" nanoassemblies at different molar ratios

increased with the number of pyridyl rings thus reflecting a dynamic equilibrium between the QD and porphyrin molecules: $<1.5 \times 10^{5} \mathrm{M}^{-1}$ for $\mathrm{H}_{2} \mathrm{P}-(\mathrm{m}-\mathrm{Pyr})_{1} ; 3.4 \times$ $10^{6} \mathrm{M}^{-1}$ for $\mathrm{H}_{2} \mathrm{P}-\left(\mathrm{m}^{\wedge} \mathrm{Pyr}\right)_{2} ; 7.8 \times 10^{6} \mathrm{M}^{-1}$ for $\mathrm{H}_{2} \mathrm{P}-(\mathrm{m}-\mathrm{Pyr})_{3}$ and $2.6 \times 10^{7} \mathrm{M}^{-1}$ for $\mathrm{H}_{2} \mathrm{P}-(\mathrm{m}-\mathrm{Pyr})_{4}$. The comparison of $\mathrm{K}_{\mathrm{C}}$ values estimated for "QD-porphyrin" nanoassemblies with those calculated for porphyrin triads (see Table 1) shows that with respect to two-fold coordination they are in a comparable range but being much larger as compared to the corresponding one-point coordination. Like for porphyrin triads, the importance of the designing adapted coordination schemes has thus been also demonstrated for formation of "QD-porphyrin" nanoassemblies. In the former case, the increase of $\mathrm{K}_{\mathrm{C}}$ values with the number of pyridyl rings is less pronounced compared to $\mathrm{K}_{\mathrm{C}}$ differences of 2-3 orders of magnitude found between two- and one-point coordination in the case of porphyrin triads (see Table 1). It means that for of "QD-porphyrin" nanoassemblies the higher $K_{C}$ values for two-point interaction reflect rather the competition with one-point interaction of TOPO ligands thus leading to ligand exchange. In the latter case, allosteric effects seem to be not so important, while they play a dominant role for porphyrin triad formation. An analysis of this dynamic exchange equilibrium will be discussed in the following section.

Temporal dynamics of porphyrins and capping ligands on $Q D$ surface. In this section, we focus presumably on nanoassemblies based on TOPO-capped $\mathrm{CdSe} /$ $\mathrm{ZnS}$ QDs and $\mathrm{H}_{2} \mathrm{P}-(\mathrm{m}-\mathrm{Pyr})_{4}$ ligands showing among a series of meso-pyridyl-substituted porphyrins the most effective PL quenching of QDs at the same titration conditions (see curve 7 in Fig. 7a). It should be noted that the experimental investigation of the porphyrin-TOPO exchange dynamics accompanied by QD PL quenching is of interest for the elucidation of mechanisms of photoinduced processes in "QD-porphyrin" nanoassemblies as well as for studying the chemical topography of QD surface. With respect to "QD-porphyrin" nanoassemblies, various aspects of this problem have been thoroughly analyzed for a wide time scale, concentration and temperature range, solvent nature and QD size in our papers [45, 46, 49, 50, $64,97,103]$. Here, we would like to pick out main results and principal conclusions.

(i) Addition of the porphyrin aliquot to the QD initial solution results in an immediate decrease of the QD PL intensity faster than our time resolution of about $60 \mathrm{~s}$. In each of the samples, the initial fast PL decrease is followed by a decrease of the PL intensities on longer time scales (Figs 9a, 9b). The PL decrease decay seems to be broadly distributed reflecting the presence of different quenching processes, namely those already inherent in the pure QD sample TOPO layer changes) and those imposed by addition of the $\mathrm{H}_{2} \mathrm{P}$ resulting in assembly formation (porphyrin-TOPO exchange dynamics).

(ii) FRET efficiency increases on a time scale of minutes before it either saturates in a constant value for some more minutes (Figs 9b, 9c) or proceeds already with a slight decrease within longer time scale. In this case, FRET is a measure for the formation kinetics of "QD-porphyrin" nanoassemblies.

(iii) QD PL quenching upon titration by porphyrins scales inversely with QD concentration. The decrease for later times is an obvious result of the ongoing 
(independent of porphyrin) intrinsic PL quenching for QD (Fig. 9a) which reflects the particular dynamic processes at the QD surface and has a direct feedback on the FRET efficiency.

(iv) The QD PL quenching as a function of the number of porphyrin molecules per QD, can be described by the well-known Stern-Volmer formalism [79] appropriately modified for our case [46]:

$$
\frac{\mathrm{I}(0)}{\mathrm{I}(\mathrm{x})}=1+\int_{0}^{\infty} \mathrm{K}(\mathrm{x}) \cdot \mathrm{dx}
$$

In our approach, the Stern-Volmer function $K(x)$ reflects the QD PL quenching in "QD-porphyrin" nanoassemblies. It depends explicitly on the molar ratio $x=\left[\mathrm{C}_{\mathrm{L}}\right] /\left[\mathrm{C}_{\mathrm{QD}}\right]$ ) and is expressed as the first derivative of the experimental data plotted in Stern-Volmer representation (Fig. 10a). In this part, the main findings are as follows: (1) At constant molar ratio, the quenching constant $K(x)$ is a linear function of the reciprocal absolute concentration $[Q D]^{-1}$ (Fig. 10a). This linear dependence indicates that the underlying quenching processes have a common nature for all absolute initial concentrations of QDs. The observed linearity is changed upon molar ratio increase. This indicates that an additional ligand dynamics creates new attachment sites which also influence on the QD PL aside of the immediate assembly formation. (2) Titration experiments with QDs of a variable size (Fig. 10b) show also that $K(x)$ is indeed initially constant but becomes smaller around a critical molar ratio (which we will call $x_{\mathrm{c}} \approx 1-10$ depending on QD size). This critical molar ratio $x_{\mathrm{c}}$ increases more or less systematically with the QD diameter.

(v) Ensemble and single object experiments for "QD-perylene-diimide" nanoassemblies show that the number of attached dye molecules to a QD is much less than that given by the molar ratio $x[40,47]$. We assume that a similar situation holds also for porphyrin ligands just after titration step. Indeed, QD PL quenching is still increasing in the presence of $\mathrm{H}_{2} \mathrm{P}$ while also FRET increases at long waiting times (see Fig. 10c) up to $>24 \mathrm{~h}$. It means that at very high $\mathrm{H}_{2} \mathrm{P}$ concentrations and long waiting times the TOPO capping shell becomes nearly completely replaced by $\mathrm{H}_{2} \mathrm{P}$ molecules.

Thus, the whole set of our results in this direction being obtained here and recently $[46,49,50,97]$ indicates the following complexation picture. Because of the presence of a limited number of empty attachment sites on the QD surface, QD PL quenching in "QD-porphyrin" nanoassemblies occurs in two steps at least. Firstly, immediately after titration, nanoassemblies are effectively formed, which results in both QD PL quenching and FRET QD $\rightarrow \mathrm{H}_{2} \mathrm{P}$. Secondly, during the waiting time (on much slower timescales) more porphyrin molecules become attached in a competition with capping TOPO molecules. Then, after saturating the empty attachment sites, the quencher molecules may be attached to the QD surface only after reorganisation of the ligand shell. The timescale of such processes is typically between 60 and $2000 \mathrm{~s}$ in the present experiments and depends critically on the experimental conditions, such as the type of QD, TOPO, unknown impurities and/or dye concentration. Correspondingly, in addition to FRET, the titration step also favors other competitive quenching mechanism (electron tunneling in the conditions of quantum confinement). It means that the exciton relaxation dynamics in QD initiated by a single titration step is not only due to the added porphyrin molecules themselves, but also to a local change in the capping ligand shell on QD surface upon nanocomposite formation as well as to a local replacement

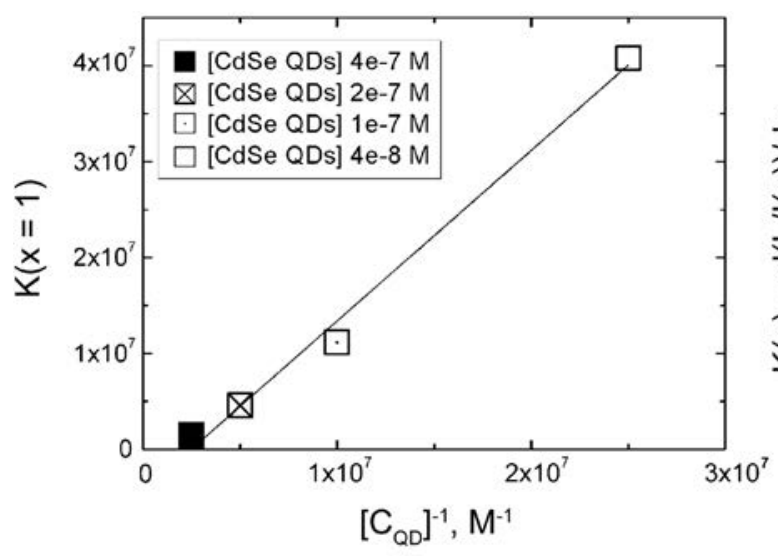

(a)

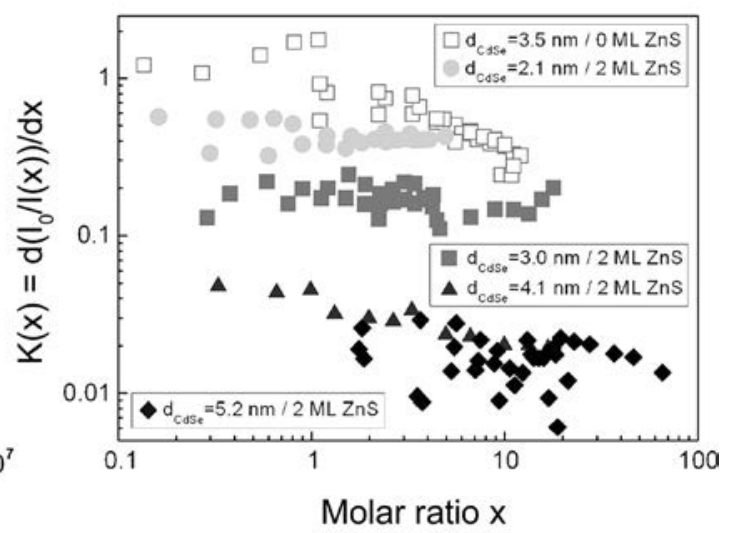

(b)

Fig. 10. Dependence of Stern-Volmer values $K(x)$ on $\mathrm{QD}$ initial concentration $\left[\mathrm{C}_{\mathrm{QD}}\right]$ (a) and QD size (b) for "QD-porphyrin" nanocomposites in toluene at $293 \mathrm{~K}$ [49]: (a): The slope $K(x=1)$ (low-molar-ratio regime at constant molar ratio) upon the increase of QD initial concentration $\left[\mathrm{C}_{\mathrm{QD}}\right]$. (b): PL quenching as a function of the molar ratio $x$ for QDs of various sizes and types (without and with $2 \mathrm{ZnS}$ monolayers, $\mathrm{ML}$ ) at fixed $\mathrm{QD}$ initial concentration $\left[\mathrm{C}_{\mathrm{QD}}\right]=1 \times 10^{-7} \mathrm{M} . K(x)$ values (reflecting QD PL quenching) were evaluated according to Equation 10. The double logarithmic plot shows the clear dependence of the PL quenching on the QD size 
of TOPO by $\mathrm{H}_{2} \mathrm{P}$ molecules. It should be mentioned also that the capping ligand coverage (TOPO or amines), and thus, the number of accessible attachment sites are controlled by the solvent properties.

It should be mentioned also that our first experiments have shown [106] that in addition to processes on a timescale below $2000 \mathrm{~s}$, a further reorganization of the surfactant shell (accompanied by increased quenching) occurs on much longer timescales. We do not yet have an explanation for this finding, but it might be related to the formation of new TOPO structures, such as surfactant islands on the QD surface or TOPO micelles in solution. On the other hand, as has been discussed recently in papers of other groups [38, 57, 89, 93], ligand adsorption and chemisorption processes (depending on the solvent properties and organic ligand nature) may control the QD-ligand interface heterogeneity, QD surface morphology and QD photophysics in solution-phase QD-ligand nanocomposites. Thus, it is not excluded that on long time scale QD surface reconstruction may compete with ligand molecules reorganization.

The presented spectroscopic approach allows investigating temporal ligand dynamics for "QD-dye" nanocomposites at extremely low concentrations of concurrent ligand-type organic molecules (porphyrins, perylene-bisimides, etc.).

\section{CONCLUSIONS}

The presented results show that because of their unique properties porphyrin-type molecules are still widely employed as suitable building blocks for the supramolecular engineering. The self-assembly bottom-up strategy based on two-point non-covalent coordination of $\mathrm{Zn}$-porphyrin chemical dimers by mesopyridyl substituted tetrapyrrole extra-ligands, have been exploited to form structurally defined self-assembled porphyrin triads of variable geometry and composition. The triads are characterized by fast (within few ps) energy and/or charge transfer leading to a strong quenching of the dimer fluorescence. Using these results and steadystate absorption/fluorescence titration measurements, the complexation constants have been quantitatively evaluated for the triads $\left[\mathrm{K}_{\mathrm{C}} \sim(0.5 \div 70) \times 10^{6} \mathrm{M}^{-1}\right]$ showing noticeable dependence on the structural parameters of the interacting subunits as well as on the solvent nature.

In addition, we highlight that "bottom-up" approach based on non-covalent coordination interactions has been successfully extended to anchor (in a systematic and directed way) porphyrin molecules on the surface of TOPO-capped semiconductor $\mathrm{CdSe} / \mathrm{ZnS}$ QDs in various solvents. The formation of "QD-porphyrin" nanoassemblies becomes more effective upon increase of the number of meso-pyridyl rings and takes place in competition with surface stabilizing tri- $n$-octyl phosphine oxide (TOPO) ligand molecules. With respect to two-fold extra-coordination, complexation constant values $\mathrm{K}_{\mathrm{C}}$ for "QD-porphyrin" nanoassemblies are in a range comparable with those obtained for various porphyrin triads. In "QD-porphyrin" nanoassemblies, because of the presence of a limited number of empty attachment sites on the QD surface, self-assembly process realizes at least two time scales: the first faster than $60 \mathrm{~s}$ by saturation of empty attachment sites and the second slower than $600 \mathrm{~s}$, which is attributed to a reorganisation of TOPO ligand shell and/or QD surface reconstruction. Correspondingly, it manifests itself in a specific nonmonotonous QD PL quenching (e.g. caused by FRET and electron tunneling of confined exciton). It was shown that the sensitivity of QD surface morphology to attached organic ligands (e.g. porphyrins) provides an opportunity to control the dynamics and pathways of the exciton relaxation in "QD-dye" nanoassemblies by changing the structure and electronic properties of these ligands. On the basis of a combination of ensemble and single molecule spectroscopy of nanocomposites, we have shown also that functionalized porphyrin molecules can be considered as extremely sensitive probes for studying the complex interface physics and exciton relaxation processes in QDs.

\section{Acknowledgements}

This work was supported by Volkswagen Foundation (Priority Program "Physics, Chemistry and Biology with Single Molecules"), DFG GRK 829/3 (“Accumulation of single molecules to nanostructure"), German Academic Exchange Service (DAAD, Grant No. A/08/08573, EZ), and Belarussian State Program for Scientific Research "Convergence 3.2.08 - Photophysics of Bioconjugates, Semiconductor and Metallic Nanostructures and Supramolecular Complexes and Their Biomedical Applications". Prof. E. Zenkevich thanks B.I. Stepanov Institute of Physics NAS, Minsk, Belarus and the DFG FOR877 ("From local constraints to macroscopic transport") for financial support. We thank our collaborators Dr. A. Shulga (synthesis of all tetrapyrrole monomers and Zn-dimers) and Dr. T. Blaudeck (now at ENAS, Chemnitz), for performing mutual experiments, theoretical analysis and fruitful discussions in Chemnitz. We also thank Prof. Dr. S.V. Gaponenko (B.I. Stepanov Institute of Physics, National Academy of Sciences, Minsk, Belarus) for fruitful discussion and Prof. F. Cichos (now at Molecular Nanophotonics, University of Leipzig, Germany) for stimulating and guiding many of the experiments.

\section{REFERENCES}

1. Muraoka T and Kinbara K. J. Photochem. Photobiol., C 2012; 13: 136-147.

2. Hirst AR, Escuder B, Miravet JF and Smith DK. Angew. Chem., Int. Ed. 2008; 47: 8002-8018.

3. Zhang L and Webster TJ. Nano Today 2009; 4: 66-80. 
4. Gawenda S, Podborska A, Macyka W and Szaciłowski K. Nanoscale 2009; 1: 299-316.

5. Moyano DF, Goldsmith M, Solfiell DJ, LandesmanMilo D, Miranda OR, Peer D and Rotello VM. J. Am. Chem. Soc. 2012; 134: 3965-3967.

6. De Mello Donega C. Chem. Soc. Rev. 2011; 40: 1512-1546.

7. Talapin DV, Lee J-S, Kovalenko MV and Shevchenko EV. Chem. Rev. 2010; 110: 389-458.

8. Mocatta D, Cohen G, Schattner J, Millo O, Rabani E and Banin U. Science 2011; 332: 77-81.

9. Liang G-X, Li L-L, Liu H-Y, Zhang J-R, Burda C and Zhu J-J. Chem. Commun. 2010; 46: 2974-2976.

10. Cheng H-M. Chem. Commun. 2011; 47: 6763-6783.

11. Handbook of Molecular Self-Assembly: Principles, Fabrication and Devices, Peinemann K-V and Barboiu M. (Eds.) Pan Stanford Publishing Co. Pte. Ltd.: Singapore, 2012.

12. Freiberg A and Trinkunas G. In Unraveling the Hidden Nature of Antenna Excitations, Laisk A, Nedbal L and Govindjee (Eds.) Springer Science+Media B.V.: Amsterdam, 2009; pp. 55-82.

13. Unterkofler S, Pflock T, Southall J, Cogdell RJ and Koehler J. ChemPhysChem. 2011; 12: 711-716.

14. Renger T and Schlodder E. J. Photochem. Photobiol., B 2011; 104: 126-141.

15. Mansoori GA. Principles of Nanotechnology. Molecular-Based Study of Condensed Matter in Small Systems, University of Illinois at Chicago: Chicago, USA, 2005.

16. Nicolini C. In Nanotechnology and Nanobiosciences, Vol. 1, Chapter 1 "Nanoscale Materials", Pan Stanford Series on Nanobiotechnology, 2010.

17. Zenkevich EI and von Borczyskowski C. In Handbook of Porphyrin Science with Application to Chemistry, Physics, Materials Science, Engineering, Biology and Medicine, Vol. 22, Kadish KM, Smith KM and Guilard R. (Eds.) World Scientific Publishing Co. Pte. Ltd.: Singapore, 2012; Chapter 104, pp. 68-159.

18. Maligaspe E, Kumpulainen T, Lemmetyinen $\mathrm{H}$, Tkachenko NV, Subbaiyan NK, Zandler ME and D’Souza F. J. Phys. Chem. A. 2010; 14: 268-277.

19. Medforth CJ, Wang Z, Martin KE, Song Y, Jacobsen JL and Shelnutt JA. Chem. Commun. 2009; 7261-7277.

20. Colvin MT, Ricks AB, Scott AM, Smeigh AL, Carmieli R, Miura T and Wasielewski MR. J. Am. Chem. Soc. 2011; 133: 1240-1243.

21. Liu J-Y, El-Khouly ME, Fukuzumi S and Ng DKP. Chem.-Eur. J. 2011; 17: 1605-1613.

22. Bottari G, Suanzes JA, Trukhina O and Torres T. J. Phys. Chem. Lett. 2011; 2: 905-913.

23. Selektor SL, Sheinina LS, Shokurov AV, Raitman OA, Arslanov VV, Lapkina LA, Gorbunova YuG and Tsivadze AYu. Protection of Metals and Physical Chemistry of Surfaces 2011; 47: 447-456.
24. Duvanel G, Grilj J and Vauthey E. J. Phys. Chem. A. 2013; 117: 918-928.

25. Peuntinger K, Lazarides T, Dafnomili D, Charalambidis G, Landrou G, Kahnt A, Sabatini RP, McCamant DW, Gryko DT, Coutsolelos AG and Guldi DM. J. Phys. Chem. C. 2013; 117: 1647-1655.

26. Zenkevich EI, Gaponenko SV, Sagun EI and von Borczyskowski C. Reviews in Nanoscience and Nanotechnology 2013; 2: No 3, 184-207.

27. Klimov V. In Handbook of Nanostructured Materials and Nanotechnology, Vol. 4, Nalwa HS. (Ed.) Academic Press: USA, 2000; pp 451-527.

28. Woggon U. Optical Properties of Semiconductor Quantum Dots, Springer: Berlin, 2006.

29. Semiconductor Nanocrystal Quantum Dots: Synthesis, Assembly, Spectroscopy and Applications, Rogach AL. (Ed.) Springer-Verlag: Wien, 2008.

30. Gaponenko SV. Introduction to Nanophotonics, Cambridge University Press: Cambridge, 2010.

31. Coe-Sullivan S, Woo W-K, Steckel JS, Bawendi M and Bulovic V. Electronics 2003; 4: 123-130.

32. Wang M, Moon S-J, Xu M, Chittibabu K, Wang P, Cevey-Ha N-L, Humphry-Baker R, Zakeeruddin SM and Graetzel M. Small 2010; 6: 319-324.

33. Medintz IL, Stewart MH, Trammell SA, Susumi K, Delahanty JB, Mey BC, Melinger JS, Blanco-Canosa JB, Dawson FE and Mattoussi H. Nature Materials 2010; 9: 676-684.

34. Frasco MF and Chaniotakis N. Sensors 2009; 9: 7266-7286.

35. Lee JRI, Whitley HD, Meulenberg RW, Wolcott A, Zhang JZ, Prendergast D, Lovingood DD, Strouse GF, Ogitsu T, Schwegler E, Terminello LJ and van Buuren T. Nano Lett. 2012; 12: 2763-2767.

36. Nabiev I, Rakovich A, Sukhanova A, Lukashev E, Zagidullin V, Pashchenko V, Rakovich YP, Donegan $\mathrm{JF}$, Rubin $\mathrm{AB}$ and Govorov $\mathrm{AO}$. Angew. Chem. Int. Ed. 2010; 49: 7217-7221.

37. Kilina $S$, Velizhanin KA, Ivanov $S$, Prezhdo OV and Tretiak S. ACS Nano 2012; 6: 6515-6524.

38. McArthur EA, Godbe JM, Tice DB and Weiss EA. J. Phys. Chem. C. 2012; 116: 6136-6142.

39. Zenkevich EI and von Borczyskowski C. High Energy Chemistry 2009; 43: 570-576.

40. Kowerko D, Krause S, Amecke N, Abdel-Mottaleb $\mathrm{M}$, Schuster J and von Borczyskowski C. Inter. Journal of Mol. Sci. 2009; 10: 5239-5256.

41. Chernook AV, Shulga AM, Zenkevich EI, Rempel U and von Borczyskowski C. J. Phys. Chem. 1996; 100: 1918-1926.

42. Bachilo S, Willert A, Rempel U, Shulga AM, Zenkevich EI and von Borczyskowski Ch. J. Photochem. Photobiol., A 1999; 126: 99-112.

43. Zenkevich EI, Shulga AM, Bachilo SM, Rempel $\mathrm{U}$, von Richthofen J and von Borczyskowski C. J. Luminescence 1998; 76\&77: 354-358. 
44. Zenkevich EI, von Borczyskowski $\mathrm{C}$ and Shulga AM. J. Porphyrins and Phthalocyanines 2003; 7: 731-754

45. Zenkevich E, Cichos F, Shulga A, Petrov E, Blaudeck T and von Borczyskowski C. J. Phys. Chem. B. 2005; 109: 8679-8692.

46. Blaudeck T, Zenkevich E, Cichos $F$ and von Borczyskowski C. J. Phys. Chem. C. 2008; 112: 20251-20257.

47. Kowerko D, Schuster J, Amecke N, Abdel-Mottaleb M, Dobrawa R, Wuerthner F and von Borczyskowski C. Phys. Chem. Chem. Phys. 2010; 12: 4112-4123.

48. Zenkevich EI, Sagun EI, Knyukshto VN, Stasheuski AS, Galievsky VA, Stupak AP, Blaudeck T and von Borczyskowski C. J. Phys. Chem. C. 2011; 115: 21535-21545.

49. Blaudeck T, Zenkevich E, Abdel-Mottaleb M, Szwaykowska K, Kowerko D, Cichos F and von Borczyskowski C. ChemPhysChem. 2012; 13: 959-972.

50. Zenkevich EI, Stupak AP, Kowerko D and von Borczyskowski C. Chem. Phys. 2012; 406: 21-29.

51. Clapp R, Medintz IL and Mattoussi H. ChemPhysChem. 2006; 7: 47-57.

52. Dayal S and Burda C. J. Amer. Chem. Soc. 2007; 129: 7977-7981.

53. Ren T, Mandal PK, Erker W, Liu Z, Avlasevich Y, Puhl L, Müllen K and Basché T. J. Am. Chem. Soc. 2008; 130: 17242-17243.

54. Bullen C and Mulvaney P. Langmuir 2006; 22: 3007-3013.

55. von Holt B, Kudera S, Weiss A, Schrader T, Manna L, Parak WJ and Braun M. J. of Mater. Chem. 2008; 18: $2728-2732$.

56. Frenzel J, Joswig J-O and Seifert G. J. Phys. Chem. C. 2007; 111: 10761-10770.

57. Knowles KE, McArthur EA and Weiss EA. Acs Nano. 2011; 5: 2026-2035.

58. Sauvage J-P. Science 2001; 291: 2105-2108.

59. Burrell AK and Wasielewski MR. J. Porphyrins and Phthalocyanines 2000; 4: 401-409.

60. Oksanen JAI, Zenkevich EI, Knyukshto VN, Pakalnis S, Hynninen PH and Korrpi-Tommola JEI. Biochim. Biophys. Acta - Bioenergetics 1997; 1321: $165-178$.

61. Anderson HL, Hunter CA and Sanders JKM. J. Chem. Soc., Chem. Commun. 1996; 1361-1369.

62. Balaban TS, Bhise AD, Bringmann G, Bürck J, Chappaz-Gillot C, Eichhöfer A, Fenske D, Götz DCG, Knauer M, Mizoguchi T, Mössinger D, Rösner H, Roussel C, Schraut M, Tamiaki H and Vanthuyne N. J. Am. Chem Soc. 2009; 131: 14480-14492.

63. Webb SI and Sanders JKM. Inorg. Chem. 2000; 39: 5912-5919.
64. Kilin DS, Tsemekhman K, Prezhdo OV, Zenkevich EI and von Borczyskowski C. J. Photochem. Photobiol., A 2007; 190: 342-354.

65. Gust D, Moore TA, Moore AL, Kang HK, De Graziano JM, Liddell PA and Seely GR. J. Phys. Chem. 1993; 97: 13637-13642.

66. Hunter CA and Hyde RK. Angew. Chem., Int. Ed. Engl. 1996; 35: 1936-1954.

67. Shinoda S, Tsukube H, Nishimura Y, Yamazaki I and Osuka A. Tetrahedron 1997; 53: 13657-13662.

68. Knyukshto VN, Sagun EI, Shulga AM and Zenkevich EI. J. Appl. Spectrosc. 1998; 65: 900-907.

69. Perrin MH, Gouterman M and Perrin CL. J. Chem. Phys. 1969; 50: 4173-4150.

70. Zenkevich EI, von Borczyskowski C, Shulga AM, Bachilo SM, Rempel U and Willert A. Chem. Phys. 2002; 275: 185-209.

71. Benesi HA and Hildebrand JH. J. Am. Chem. Soc. 1949; 71: 2703-2707.

72. Leggett DJ, Kelly SL, Shiue LR, Wu YT, Chang D and Kadish KM. Talanta 1983; 30: 579-586.

73. Mukherjee P, Chattopadhyay S and Bhattacharya S. J. Porphyrins Phthalocyanines 2012; 16: 14-24.

74. Hoenigman SM and Evans CE. Anal Chem. 1996; 68: 3274-3276.

75. Kubista M, Sjoback R and Albinsson B. Anal. Chem. 1993; 65: 994-998.

76. Abdollahi H and Nazari F. Anal. Chim. Acta 2003; 486: 109-123.

77. Encinas MV and Lissi EA. Chem. Phys. Lett. 1982; 91: $55-57$.

78. Shoenfeld PS and Devoe JR. Anal. Chem. 1976; 48: 403R-411R.

79. Lakowicz JR. Principles of Fluorescence Spectroscopy (2nd Ed.), Kluwer Academic/Kluwer Publishers: New York, 1999.

80. Imahori H, Yamada K, Yoshizawa E, Okada T and Sakata Y. J. Porphyrins Phthalocyanines 1997; 1: $55-62$.

81. Tabushi I, Kugimiya S, Kinnaird MG and Sasaki T. J. Am. Chem. Soc. 1985; 107: 4192-4199.

82. Anderson S, Anderson HL and Sanders JKM. Angew. Chem., Int. Ed. Engl. 1992; 31: 907-919.

83. Lendzian F and von Maltzan B. Chem. Phys. Lett. 1991; 180: 191-194.

84. Osuka A, Maruyama K, Yamazaki I and Tamai N. Chem. Phys. Lett. 1985; 107: 482-486.

85. Zenkevich EI, Shulga AM, Chernook AV, Sagun EI and Gurinovich GP. Khimicheskaya Fizika. 1989; 8: 842-853.

86. Knop JV and Fuhrhop JH. Z. für Naturforsch. 1970; 25b: 729-734.

87. Mansur HS and Mansur AAP. Mater. Chem. Phys. 2011; 125: 709-717.

88. Bullen C and Mulvaney P. Langmuir 2006; 22: 3007-3013. 
89. Knowles KE, Tice DB, McArthur EA, Solomon GC and Weiss EA. J. Am. Chem. Soc. 2010; 132: 1041-1060.

90. Dayal S, Lou Y, Samia ACS, Berlin JC, Kenney ME and Burda C. J. Am. Chem. Soc. 2006; 128: 13974-13975.

91. Fritzinger B, Capek RK, Lambert K, Martins JC and Hens Z. J. Am. Chem. Soc. 2010; 132: $10195-10201$.

92. Ren T, Mandal PK, Erker W, Liu Z, Avlasevich Y, Puhl L, Müllen K and Basché T. J. Am. Chem. Soc. 2008; 130: 17242-17243.

93. Knowles KE, Frederick MT, Tice DB, MorrisCohen AJ and Weiss EA. J. Phys. Chem. Lett. 2012; 3: $18-26$.

94. Schmitt FJ. J. Optics 2010; 12: 084008.

95. Krebs FC, Senkovskyy V and Kiriy A. IEEE J. Selected Topics of Quantum Electronics 2010; 16: $1821-1826$.

96. Marjanovic N, Hammerschmidt J, Perelaer J, Farnsworth S, Rawson I, Kus M, Yenel E, Tilki S, Schubert US and Baumann RR. J. Mater. Chem. 2011; 21: 13634-13638.

97. Zenkevich EI, Sagun EI, Yarovoi AA, Shulga AM, Knyukshto VN, Stupak AP and von Borczyskowski C. Optics and Spectroscopy 2007; 103: 998-1009.
98. Mattoussi H, Mauro JM, Goldman ER, Anderson JP, Sundar VC, Mikulec FV and Bawendi MG. J. Am. Chem. Soc. 2000; 122: 12142-12151.

99. Chernook AV, Rempel U, von Borczyskowski C, Zenkevich EI and Shulga AM. Chem. Phys. Lett. 1996; 254: 229-241.

100. Zenkevich EI and von Borczyskowski C. In Multiporphyrin Arrays: Fundamentals and Applications, Kim D. (Ed.) Pan Stanford Publishing Pte. Ltd.: Singapore, 2012; Chapter 5, pp 217-288.

101. Issac A, von Borczyskowski $\mathrm{C}$ and Cichos F. Phys. Rev. B. 2005; 71: 161302 (R).

102. Cichos F, von Borczyskowski C and Orrit M. Current Opinion in Colloid \& Interface Science 2007; 12: 272-289.

103. Zenkevich E, Blaudeck T, Shulga A, Cichos F and von Borczyskowski C. J. Luminescence 2007; 122123: $784-788$.

104. Tachiya MJ. J. Chem. Phys. 1982; 76: 340-348.

105. Song N, Zhu H, Jin S, Zhan W and Lian T. ACS Nano. 2011; 5: 613-621.

106. Zenkevich EI, Blaudeck T, Abdel-Mottaleb MMS, Cichos F, Shulga AM and von Borczyskowski C. Int. J. Photoenergy 2006; 90242. 